\title{
Enhanced biodegradation of PAHs in historically contaminated soil by $M$. gilvum inoculated biochar
}

Bijing Xiong, ${ }^{\mathrm{a}, \mathrm{b}}$, Youchi Zhang ${ }^{\mathrm{a}}$, Yanwei Hou ${ }^{\mathrm{c}}$, Hans Peter H. Arp ${ }^{\mathrm{d}}$, Brian J. Reid ${ }^{\mathrm{a}, \mathrm{e}}$, Chao Cai ${ }^{\mathrm{a}, *}$

${ }^{a}$ Key Lab of Urban Environment and Health, Institute of Urban Environment, Chinese Academy of Sciences, Xiamen 361021, China

${ }^{\mathrm{b}}$ University of Chinese Academy of Sciences, Beijing 100049, China

${ }^{\mathrm{c}}$ Department of Environmental Science and Engineering, Huaqiao University,

Xiamen 361021, China

d Norwegian Geotechnical Institute (NGI), P.O. Box 3930, Ullevål Stadion, N-0806 Oslo, Norway

${ }^{\text {e }}$ School of Environmental Sciences, University of East Anglia, Norwich, NR4 7TJ, UK

* Corresponding author

Email address: ccai@iue.ac.cn (Chao Cai), bjxiong@iue.ac.cn (Bijing Xiong), yczhang@iue.ac.cn (Youchi Zhang), houyw@hqu.edu.cn (Yanwei Hou), Hans.Peter.Arp@ngi.no (Hans Peter H. Arp), B.Reid@uea.ac.uk (Brian J. Reid)

\section{Corresponding author:}

E-mail: ccai@iue.ac.cnＰhone: + 86-0592-6190551

Fax: +86-592-6190977 Postal address: 1799 Jimei Road, Xiamen 361021 China 
1 ABSTRACT: The inoculation of rice straw biochar with PAH-degrading

2 Mycobacterium gilvum $\left(1.27 \times 10^{11} \pm 1.24 \times 10^{10}\right.$ cell $\left.\mathrm{g}^{-1}\right)$, and the subsequent amendment

3 of this composite material to PAHs contaminated $\left(677 \mathrm{mg} \mathrm{kg}^{-1}\right)$ coke plant soil, was

4 conducted in order to investigate if would enhance PAHs biodegradation in soils. The

5 microbe-biochar composite showed superior degradation capacity for phenanthrene,

6 fluoranthene and pyrene. Phenanthrene loss in the microbe-biochar composite, free cell

7 alone and biochar alone treatments was, respectively, $62.6 \pm 3.2 \%, 47.3 \pm 4.1 \%$ and non-

8 significant $(\mathrm{P}>0.05)$; whereas for fluoranthene loss it was 52.1 $\pm 2.3 \%$; non-significant

$9 \quad(\mathrm{P}>0.05)$ and non-significant $(\mathrm{P}>0.05)$; and for pyrene loss it was $62.1 \pm 0.9 \% ; 19.7 \pm 6.5 \%$

10 and $13.5 \pm 2.8 \%$. It was hypothesized that the improved remediation was underpinned

11 by i) biochar enhanced mass transfer of PAHs from the soil to the carbonaceous biochar

12 "sink", and ii) the subsequent degradation of the PAHs by the immobilized M. gilvum.

13 To test this mechanism, a surfactant (Brij 30; $20 \mathrm{mg} \mathrm{g}^{-1}$ soil), was added to impede

14 PAHs mass transfer to biochar and sorption. The surfactant increased solution phase

15 PAH concentrations and significantly $(\mathrm{P}<0.05)$ reduced $\mathrm{PAH}$ degradation in the biochar

16 immobilized $M$. gilvum treatments; indicating the enhanced degradation occurred

17 between the immobilized M. gilvum and biochar sorbed PAHs.

18 Keywords:

19 PAHs

20 Biochar

21 Microbe immobilization

22 Soil

23 Degradation 
Abbreviations

$\mathrm{PAHs}^{1}, \mathrm{AC}^{2}, \mathrm{BC}^{3}$

$\mathrm{HA}^{4}, \mathrm{DOC}^{5}, \mathrm{CP}$ soil ${ }^{6}$

$\mathrm{BET}^{7}$, M. gilvum ${ }^{8}, \mathrm{MM}^{9}$

$\mathrm{LB}^{10}, \mathrm{SEM}^{11}, \mathrm{qPCR}^{12}$

$\mathrm{CPD}^{13}, \mathrm{EPS}^{14}, \mathrm{DLVO}^{15}$

$\mathrm{CSH}^{16}, \mathrm{PHE}^{17}, \mathrm{FLA}^{18}, \mathrm{PYR}^{19}$

${ }^{1}$ Polycyclic aromatic hydrocarbons

2 Activated carbon

${ }^{3}$ Biochar

${ }^{4}$ Humic acids

${ }^{5}$ Dissolved organic carbon

${ }^{6}$ Beijing coking plant soil

${ }^{7}$ Brunauer-Emmett-Teller

${ }^{8}$ Mycobacterium gilvum

${ }^{9}$ Minimal medium

${ }^{10}$ Lysogeny Broth

11 Scanning electron microscopy

${ }^{12}$ Real time quantitative PCR

${ }^{13}$ Critical-point drying

${ }^{14}$ Extracellular polymeric substances

${ }_{15}$ Derjaguin-Landau-Verwey-Overbeek theory

${ }^{16}$ Cell surface hydrophobicity

${ }_{17}$ Phenanthrene

${ }^{18}$ Fluoranthene

${ }^{19}$ Pyrene 


\section{Introduction}

Polycyclic aromatic hydrocarbons (PAHs) are carcinogenic and mutagenic compounds (Mastrangelo, Fadda et al. 1996, Goldman, Enewold et al. 2001). Their ubiquitous occurrence (Samanta, Singh et al. 2002), intrinsic toxicity (Mastrangelo, Fadda et al. 1996, Goldman, Enewold et al. 2001) and bioaccumulation potential (Baussant, Sanni et al. 2001) raise significant concerns for human and ecosystem health, wherever PAHs are present at elevated concentrations, such as those found in urban or industrial soils (Wagrowski and Hites 1996, Bakker, Casado et al. 2000, Tang, Tang et al. 2005).

Developing cost-effective methods to clean up PAHs from contaminated land remains a technological challenge (Gan, Lau et al. 2009). One approach is to lower the bioavailability of PAHs through the introduction of sorbent amendments, to strongly bind the PAHs, and thereby reduce exposure and associated risks (Ghosh, Luthy et al. 2011). The most extensively studied amending agents for such purposes, being a sorption "sink" for PAHs, are carbonaceous materials such as activated carbon (AC) and biochars (Beesley, Moreno-Jiménez et al. 2011, Hale, Hanley et al. 2011, Lehmann and Joseph 2012, Oleszczuk, Hale et al. 2012). Such carbonaceous materials have been observed to sorb PAHs up to 10-1000 times stronger (per unit mass) than other types of soil organic carbon (Accardi-Dey and Gschwend 2003, Cornelissen and Gustafsson 2004). When a strong sorbent, like biochar or AC, is introduced to a contaminated soil, the contaminants are transferred from the aqueous phase and weaker sorption (fastdesorption) sites of the contaminated soil to the strong sorption site of the added sorbent (Werner, Ghosh et al. 2006, Rhodes, Carlin et al. 2008, Cho, Werner et al. 2012, Oleszczuk, Hale et al. 2012, Liu, Chen et al. 2015). As an example, the uptake of polychlorinated biphenyls in passive samplers decreased up to $73 \%$ with amendment 
of $3.7 \%$ of AC after 5 years (Cho, Werner et al. 2012). Though AC can sorb PAHs more effectively than biochars (Cornelissen, Breedveld et al. 2006, Gomez-Eyles, Yupanqui et al. 2013), biochars offer other advantageous traits, such as lower cost, the ability to be made from organic waste materials, and reduced (or even negative) $\mathrm{CO}_{2}$ emissions associated with their production (Lehmann 2007, Lehmann and Joseph 2015).

One significant disadvantage of sorbent amendments is that they generally lead to reduced biodegradation of PAHs because the sorbed PAHs have a reduced microbial bioaccessibility and cannot, therefore, be degraded (Rhodes, Carlin et al. 2008, Rhodes, McAllister et al. 2010, Cho, Werner et al. 2012, Arp, Lundstedt et al. 2014). For example, the mineralization extent of phenanthrene (PHE) decreased by up to $50 \%$ with amendment of 5\% BC (Rhodes, Carlin et al. 2008); whereas for AC amendment, it declined from $87.2 \%$ (in absence of AC) to $0.4 \%$ (5\% AC) (Rhodes, McAllister et al. 2010). This is potentially problematic as many regulatory standards, and site-specific remediation targets, are based on total concentrations, and not bioavailable concentrations (Latawiec, Swindell et al. 2010, Ortega-Calvo, Harmsen et al. 2015). Therefore, establishing technologies that both lower total soil concentration (via biodegradation) and bioavailability through sorption and entrapment would be advantageous.

These conflicting goals might be reconciled through the impregnation of sorbent amendments with PAH-degrading microorganisms (Wick, Springael et al. 2001, Wick, De Munain et al. 2002, Uyttebroek, Ortega-Calvo et al. 2006). Through such an approach the mass transfer of PAHs from contaminated soil to the degrading microbial community might be enhanced, and in addition there would be an enrichment of degrading bacteria and biofilm formation on the strong sorbing materials (Bastiaens, Springael et al. 2000, Wick, Springael et al. 2001, Uyttebroek, Ortega-Calvo et al. 2006), 
which could provide to stimulate the biodegradation of PAHs (Liu, Chen et al. 2015). Supporting this reasoning, additions of humic acids (HA) (Smith, Thullner et al. 2009), model synthetic amberlite sorbents (Uyttebroek, Ortega-Calvo et al. 2006), clay (Ortega-Calvo and Saiz-Jimenez 1998), and dissolved organic carbon (DOC) (Haftka, Parsons et al. 2008) have been shown to promote both PAH sorption and degradation. Particularly, a 4.8- and 9.5-folds increase in PHE degradation rates was respectively observed when in the presence of HA (Smith, Thullner et al. 2009) and model synthetic amberlite sorbents (Uyttebroek, Ortega-Calvo et al. 2006). It is important in this context to note that biochars, with high surface area and porosity, make good candidates for microbial habitats (Saito 1990, Pietikäinen, Kiikkilä et al. 2000, Hale, Luth et al. 2014). Microbe-AC/biochar composites have been employed in wastewater treatment process, to provide protection to microbes, and/or to increase contaminant removal performance (Morsen and Rehm 1990, Song, Edwards et al. 2006, Lin, Donghui et al. 2010). For example, a 2-times higher pyridine-degradation rate constant $\left(0.12 \mathrm{mg} \mathrm{g}_{\text {carrier }}{ }^{-1} \mathrm{~h}^{-1}\right)$ was observed when Paracoccus sp. strain KT-5 was pre-immobilzed on bamboo-carbon (Lin, Donghui et al. 2010).

Elevated metabolic activities resulting from biochar amendment to soil have also been observed (Steinbeiss, Gleixner et al. 2009), but studies focus on the application of microbe-biochar composite in the remediation of contaminated soils are rare. Therefore there is a research gap regarding the effectivity of such approaches. In order to evaluate the potential for bacteria-inoculated biochar to remediate PAH contaminated soil, we investigated the influence of pre-immobilizing the actinobacteria cells, of M. gilvum, on biochar, and quantified its ability to sorb and biodegrade PAHs in a real-world, historically contaminated soil. 


\subsection{Reagents and Chemicals}

\subsection{Soil}

A real-world, PAH contaminated soil was collected from a former Coking Plant (CP soil) (N 3951' $0.42^{\prime \prime}$, E 116 31' 38.83" ) in Beijing, China. The soil samples were stored in dark glass containers at $-80^{\circ} \mathrm{C}$ until use. The total concentrations of 16 US EPA PAHs in this soil, indicating heavy contamination, were $677 \mathrm{mg} \mathrm{kg}^{-1}$. Physical and chemical properties of $\mathrm{CP}$ soil include: $\mathrm{pH} 8.37$, total organic matter $10 \%$, total $\mathrm{N}$ $0.231 \%$, total C $12.92 \%$, total S $0.593 \%$, clay $2.39 \%$, silt $15.4 \%$, and sand $82.2 \%$ (see the Supporting Information (SI) for quantification details).

\subsection{Biochar}

Rice straw (Oryza Sativa), sewage sludge, and pig manure were applied as raw stocks to produce separate biochars by pyrolysis at $500^{\circ} \mathrm{C}$ (see the SI for more information about selection of pyrolysis temperature) for $4 \mathrm{~h}$ in a muffle furnace under limited oxygen conditions. Characteristics of the produced biochars were analyzed (see the SI 
for quantification details and results). Rice straw derived biochar was ultimately selected to study as the inoculum carrier, as the largest specific surface area $\left(68.1 \mathrm{~m}^{2} \mathrm{~g}^{-}\right.$ $\left.{ }^{1}\right)$, pore volume $\left(0.17 \mathrm{~cm}^{3} \mathrm{~g}^{-1}\right)$ and surface basic groups $\left(0.172 \mathrm{mmol} \mathrm{g}^{-1}\right)$ were observed in this biochar (Table S1 \& S2, SI), indicating a higher bacterial adsorption capability (Krisdhasima, Vinaraphong et al. 1993, Hale, Luth et al. 2015). Moreover, rice straw is a practical biomass-waste feedstock for biochar production (Wu, Yang et al. 2012). Other physical and chemical properties of this biochar were: $\mathrm{pH} 10.14$, total N 1.73\%, total C $48.6 \%$, ash content $29.3 \%$. The total concentration of 16 US EPA PAHs was $4.35 \mathrm{mg} \mathrm{kg}^{-1}$ (see the SI for quantification details).

\subsection{Bacteria strain, isolation, culture conditions, and preparation of cell}

\section{suspensions}

Mycobacteria have been reported to be adept degraders of gasoline components and sorbed PAHs (Kim, Kweon et al. 2010). As an indigenous bacteria in the tested soil, $M$. gilvum was employed. M. gilvum was isolated from the CP soil via a classical shaken liquid medium enrichment method as described elsewhere (Bastiaens, Springael et al. 2000). M. gilvum was confirmed, in preliminary tests, to be capable of degrading naphthalene, fluorene, phenanthrene, anthracene, fluoranthene (FLU), and pyrene (PYR) effectively in minimal medium (MM) solutions (described in the SI Table S3) (see the SI Figure S2). M. gilvum isolate was maintained using pyrene as the sole carbon and energy source on MM agar plates. For the preparation of cell suspensions, one loop of isolate was picked up and inoculated into a liquid Lysogeny Broth (LB, no PAHs were added). After 1 -week incubation on a rotary shaker at $30^{\circ} \mathrm{C}, 180 \mathrm{rpm}$, cell growth approached a steady state $\left(\mathrm{OD}_{600}=1.6\right)$ and cells were then harvested. The cell culture was centrifuged at $3500 \mathrm{r} \mathrm{min}^{-1}$ for $10 \mathrm{~min}$, the supernatant was discarded and sterilized 
fresh LB was added to re-suspend the cells; thereby, the cell suspension was condensed and prepared for further inoculations.

\subsection{Immobilization of M. gilvum cells on biochar}

To immobilize $M$. gilvum cells on rice straw biochar, the biochar was firstly grounded by a wood roller in valve bag and then passed through a 2-mm sieve, and $0.25 \mathrm{~g}$ biochar (dry weight) was then soaked with fresh LB (1:20, w/v) in 50 ml-flasks. Subsequently, the flasks were closed with Teflon-lined stoppers and sterilized twice at $121^{\circ} \mathrm{C}$ for 30 min. Cell suspensions were introduced to the flasks, after they had cooled, with each flask receiving $2.5 \mathrm{ml}$ of condensed cell suspension, containing $8.45 \times 10^{10}$ cells (confirmed by plate counting). The flask contents were then incubated on a rotary shaker at $30^{\circ} \mathrm{C}, 80 \mathrm{rpm}$ for $48 \mathrm{~h}$. The mixtures were separated with a $75-\mu \mathrm{m}$ sieve and rinsed with de-ionized water thrice to remove the planktonic cells. Obtained M. gilvumcomposite should be collected and stored at $4{ }^{\circ} \mathrm{C}$ if immediate inoculation into soil is not possible (Lin, Wu et al. 2015). All operations were performed under strict aseptic conditions.

The accumulated biomass of $M$. gilvum on rice straw biochar was evaluated by realtime PCR assays. To test the immobilization durability, biochar inoculated with $M$. gilvum cells, following 48-h of culturing, was reintroduced to fresh LB and then incubated on a rotary shaker $\left(30^{\circ} \mathrm{C}, 180 \mathrm{rpm} \mathrm{min}^{-1}\right)$ for 30 days. Samples incubated for $4,8,12,16,18,22,26$, and 30 day periods were collected, with three flasks being sacrificed at each sampling event. Parts of the samples were used for scanning electron microscopy (SEM) imaging, and the remainder was stored at $-80{ }^{\circ} \mathrm{C}$ until DNA extraction. 


\subsection{SEM Observation}

Biochars inoculated with M. gilvum cells were imaged using SEM. Samples were prepared by chemical fixation and critical-point drying (CPD) (Karcz, Bernas et al. 2012). Briefly, samples were fixed in $2.5 \%$ glutaraldehyde in $0.1 \mathrm{M}$ PB buffer (pH 7.2) for $2 \mathrm{~h}$. The samples were then rinsed by $0.1 \mathrm{M}$ PB buffer twice, and dehydration was carried out in a graded ethanol/water series of 30,50, 70, 90, and 100\%, at $20 \mathrm{~min}$ for each concentration. Dehydrated samples were then dried to the critical-point with carbon dioxide in a Pelco CPD2 apparatus. A 5-nm gold film was sputter-coated on the samples. Images were then recorded by SEM (Hitachi S4800) operated at $5 \mathrm{kV}$.

\subsection{Biodegradation}

A batch biodegradation experiment was conducted in 150-ml flasks. CP soil (5 grams dry weight) and $30 \mathrm{ml} \mathrm{MM}$ solutions were mixed and incubated for 72 hours to revive the soil microbes. Four different treatments were then prepared. These were: (i) raw CP soil only (the control), (ii) $5 \mathrm{~g}$ of raw CP soil inoculated with $2.5 \mathrm{ml}$ of condensed $M$. gilvum cell suspension (circa $1.69 \times 10^{10} \mathrm{CFU} / \mathrm{g}_{\mathrm{dw}}$ soil), (iii) $5 \mathrm{~g}$ of raw $\mathrm{CP}$ soil with 0.25 $\mathrm{g}$ dry weight of sterile rice straw biochar (at a ratio of $0.05 \mathrm{~g}_{\mathrm{dw} \text { biochar }} / \mathrm{g}_{\mathrm{dw}}$ soil), and (iv) 5 $\mathrm{g}$ of raw $\mathrm{CP}$ soil added with $0.25 \mathrm{~g}$ dry weight of biochar inoculated with $1.27 \times 10^{11}$ cells $/ \mathrm{g}_{\mathrm{dw}}$ biochar, resulting in a cell density in the $\mathrm{CP}$ soil of $6.43 \times 10^{9}$ cells $/ \mathrm{g}_{\mathrm{dw}}$ soil. Unavoidably, less $M$. gilvum cells were introduced in this treatment compared with direct inoculation of free cells (due to incomplete transfer of $M$. gilvum cells from the loading solution onto the biochar). Ultimately, all flasks were supplemented with more MM solutions to obtain a final volume of $50 \mathrm{ml}$ (final soil to water ratio was 1:10, w/v). For each treatment, independent biodegradation assays were performed in triplicate, and all flasks were randomly placed on a rotary shaker $(180 \mathrm{rpm})$ in the dark at $30^{\circ} \mathrm{C}$, 
205 for 18 days. Sterile MM solution was supplemented every 2 days to keep the 206 suspensions at a fixed volume. Slurries with a volume of $10 \mathrm{ml}$ were taken from all treatments for DNA extraction at day 0 and day 18.

In order to explore the hypothesized mechanism, that biochar would promote mass transfer of PAHs to the biochar and the immobilized cells would then degrade the transferred PAHs, a further set of flasks were prepared. These were identical to those described above but to each flask the anionic surfactant Brij 30 was added (20 mg g ${ }^{-1}$ soil; thereby achieving an experimental concentration of $\left.2 \mathrm{~g} \mathrm{~L}^{-1}\right)$. Brij 30 has demonstrated high PAH solubilizing ability that results in a considerable reduction of PAH sorption to biochars (53\%) (Ahn, Kim et al. 2008).

\subsection{DNA Extraction and Real-Time PCR}

DNA extraction was achieved using FastDNA SPIN kit for soil (MoBio Laboraories, Carlsbad, CA, USA), in accordance with the manufacturer's instructions. FastDNA SPIN kits have previously been used in DNA extraction from biochar amended soil (Quilliam, Marsden et al. 2012, Leite, Balieiro et al. 2014). Real time quantitative TaqMan PCR assays were conducted, targeting Mycobacterium nidA. Primer and probe sets target conserved regions determined from a multiple alignment of nidA obtained from several PAH-degrading Mycobacterium (DeBruyn, Chewning et al. 2007). The TaqMan probe sequences were 5' -FAMTCCTACCCGTCGCCGGTACA-BHQ1, forward and reverse primer sequences were 5' -TTCCCGAGTACGAGGGATAC and 5' -TCACGTTGATGAACGACAAA, respectively.

Quantitative PCR assays were performed using a real-time quantitative PCR detection system (Roche 480, Roche, Indianapolis, IN, US., Light Cycler FastStart DNA Master Hybridization Probes (Roche) was used for qPCR reactions. Reaction 
conditions were as follows: $50^{\circ} \mathrm{C}$ for $5 \mathrm{~min}, 95^{\circ} \mathrm{C}$ for $15 \mathrm{~min}$, then 40 cycles of denaturing at $94^{\circ} \mathrm{C}$ for $30 \mathrm{~s}$, annealing at $56^{\circ} \mathrm{C}$ for $30 \mathrm{~s}$, lengthening at $72^{\circ} \mathrm{C}$ for $30 \mathrm{~s}$.

231 For each sample, independent quantitative assays were carried out in triplicate. In every

232 amplification reaction, 10-fold diluted standard plasmid containing nidA genes were 233 amplified with the primers to obtain standard curves, and negative controls were also 234 included. Efficiencies of amplification were $90 \%$ to $110 \%$ for all samples.

\subsection{Analysis of PAHs}

PAHs in the soil phase and aqueous phases were analyzed as follows. Biodegradation assay flasks were allowed to settle for $1 \mathrm{~h}$, then the supernatant solution was pipetted out and stored in 80-ml K-D tubes. The remaining soils were freeze-dried, and the 16 US EPA PAHs were analyzed using a method previously reported for quantifying PAHs in biochars and biochar amended soils (Fabbri, Rombolà et al. 2013) (see the SI).

Analysis of aqueous PAHs in samples without Brij 30 amendment was carried out following a method described elsewhere (Ahn, Werner et al. 2008). Briefly, aluminum sulfate was added to the K-D tubes to flocculate suspended solids, and then hydrochloric acid was added to adjust the $\mathrm{pH}$ to 7 . The K-D tubes were capped and then shaken by hand to enhance flocculation for $3 \mathrm{~min}$, and subsequently centrifuged for 15 min at $2000 \mathrm{rpm}$ twice to remove flocs. The clear supernatant was transferred to 250$\mathrm{ml}$ size screw-capped flasks, hexane $(15 \mathrm{ml})$ was added to each flask, and the flasks were then shaken on a rotary shaker at $180 \mathrm{rpm}$ for $30 \mathrm{~min}$. The extracts were then separated using separatory funnels. Extraction of each batch of supernatant was performed three times to ensure full PAH recovery. Subsequent up-concentration and clean-up steps of the extracts are described in the SI.

The presence of Brij 30 in the aqueous phase of the surfactant dosed treatments 
precluded back extraction of the aqueous supernatant into hexane (as the surfactant causes demulsification of the mixture), and so, in these treatments, aluminum sulfate was added and the samples were shaken and centrifuged (as described above) to obtain a clear supernatant. Thereafter, PAHs were quantified using high-performance liquid chromatography (HPLC) with direct injection of the clear supernatant (Zhu and Aitken 2010).

\subsection{Statistical analysis}

Microsoft Excel software (version 2013) was used for data processing. SPSS (version 22.0) was used to verify normality of data with Shapiro-Wilk's test. Means were then compared using one-way ANOVA followed by either the LSD test or Dunnett's T3 test, depending on whether equal variances were or were not assumed, respectively, to compare differences between multiple groups.

\section{Results}

\subsection{Immobilization of M. gilvum on Biochar}

The presence of M. gilvum cells on rice straw biochars after the initial 48-h culturing or 18-day of incubation in LB after culturing was imaged using SEM, alongside images of the sterile biochar and free M. gilvum cells (Figure 1). After 48-h of culturing, the adhesion of M. gilvum cells on rice straw biochar was observed (Figure 1C). Cells were observed to frequently colonize the surface and pore entrances of the rice straw biochar. As evident from Figure 1C, the cells appear grouped together as cell aggregates, additionally extracellular polymeric substances (EPS) were observed. After 18 days, the EPS was further pronounced, as observed in Figure 1E and Figure 1F, and formed 

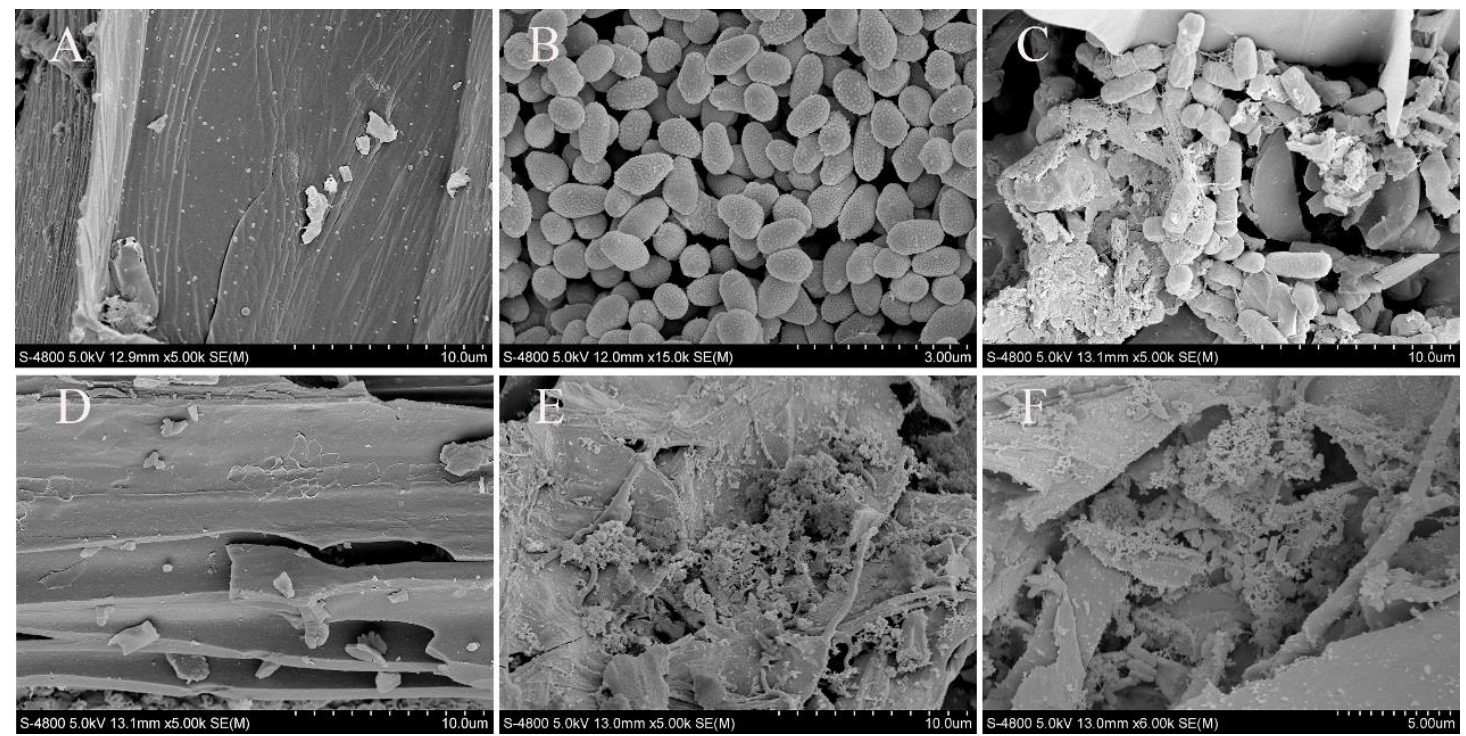

Figure 1. SEM images of samples collected after $48 \mathrm{~h}$ (A-C) and 18 days (D-F). (A) Surface structure of sterile rice straw biochar $(\times 5000)$. (B) Free M. gilvum cells with rough and raised cell walls $(\times 15000)$. (C) Cell aggregates of $M$. gilvum isolate attached on rice straw biochar after two-day culturing, and the net-like extracellular polymeric substances (EPS) formed around the cells $(\times 5000)$. (D) Surface of biochar soaked in LB for 18 days without bacteria inoculation $(\times 5000)$. (E) Biochar inoculated with $M$. gilvum cells $(\times 5000)$. (F) Same as E but showing biofilm arranged in mesh-like aggregates, and EPS visible as network-like structures extending over and in between the M. gilvum cells $(\times 6000)$.

The accumulated biomass of $M$. gilvum isolate on biochars was assessed by quantitative PCR assays (Figure 2). The initial amount of nidA copies after 48-h inoculation was $1.27 \times 10^{11} \pm 1.24 \times 10^{10}$ copies/g $\mathrm{g}_{\mathrm{dw}}$ biochar. Afterwards, the $n i d A$ copies on biochars varied during the incubation period from $2.7 \times 10^{10} \pm 9.26 \times 10^{9}$ to

$2911.1 \times 10^{11} \pm 5.3 \times 10^{9}$ copies/g $/ g_{d w}$ biochar (respectively, representing a 5 -folds decreased to a 10-folds increase). A dynamic fluctuation of nidA copies was evident by a sharp decrease in the first eight days, followed by a rapid increase over the next 10 days. Ultimately, a stationary biomass (approximated $7.0 \times 10^{10} \pm 1.5 \times 10^{9}$ copies $/ \mathrm{g}_{\mathrm{dw}}$ biochar) was maintained at 18 days. This combination of SEM imaging and qPCR assays revealed

296 that the immobilization of $M$. gilvum cells on rice straw biochar were effective and durable in LB. 


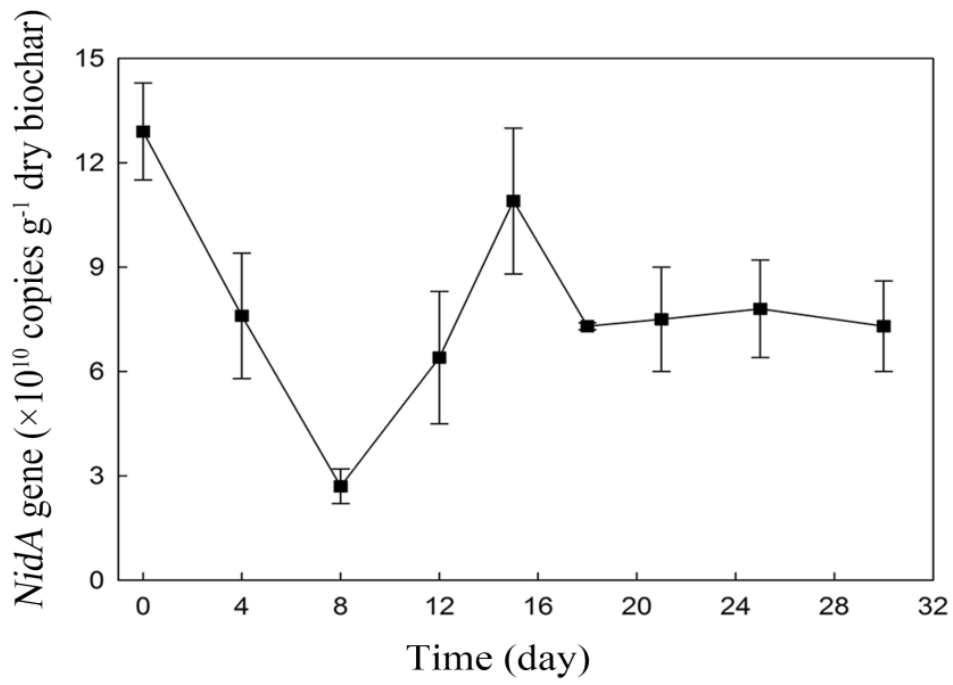

298

299

Figure 2. NidA copies on biochar for 30 days of incubation

\subsection{Biodegradation of PAHs}

A preliminary test using M. gilvum cells inoculated biochar indicated $98 \%$ removal of pyrene within 5 days when $0.5 \mathrm{~g}$ of inoculated biochar was placed in a $50 \mathrm{ml} \mathrm{MM}$ solution with $50 \mathrm{mg} \mathrm{L}^{-1}$ of pyrene (Figure S3, SI). It is anticipated that the presence of soil and other PAHs may slow down the removal rate compared to a single PAH. The residual PAHs in $\mathrm{CP}$ soil with the different treatments mentioned above were analyzed after 18 days (Table S4, SI). Recoveries of the 6 surrogate standards ranged from $78 \%$ to $99 \%$ for all samples (i.e. for acenaphthene- $d_{10}$, phenanthrene- $d_{10}$ and chrysene- $d_{12}$, they were $78 \pm 4 \%, 88 \pm 2 \%, 86 \pm 5 \%$ in soils without any treatment, and $74 \pm 3 \%, 89 \pm 7 \%$, $82 \pm 2 \%$ in soils with $5 \%$ biochar amendment, respectively). No significant difference in recoveries between raw soil and soil with $5 \%$ of biochar amendment was observed (P=0.257, 0.906, 0.319 for acenaphthene- $d_{10}$, phenanthrene- $d_{10}$ and chrysene- $d_{12}$ respectively). No corrections for recovery were made. Residual PAH concentrations in the different treatments established after 18 days are reported in Table S4 (SI).

PHE, FLA, and PYR concentrations were observed to decrease most extensively (Table S4). A preliminary experiment with PAHs in solution with M. gilvum cells 
(Figure S2) showed marked decreases in these three PAHs, as well as naphthalene, fluorene and anthracene, but not other PAHs. Naphthalene, fluorene and anthracene were degraded to a lesser extent in CP soil in comparison to PHE, PLA and PYR (Table S4). The difference in the extent of degradation for the different PAHs are suggested to relate to lower bioaccessibility of naphthalene, fluorene and anthracene in the CP soil as a consequence of native bacteria degrading these compounds in the field. This reasoning is supported by the relatively low concentrations of these three PAHs (naphthalene at $0.6 \%$, fluorene at $1.0 \%$ and anthracene at $2.5 \%$ of the total 16 US EPA PAHs concentrations (Table S4)). By contrast, PHE, FLA and PYR, respectively, contributed 11.2, 16.2 and $18.3 \%$ of the total 16 US EPA PAHs to the CP soil. Given the greater prevalence and marked reduction in their concentrations, further discussion in this study is directed towards PHE, FLA and PYR.

The loss of PHE, FLA, and PYR in the control treatments was minimal over 18 days $(<4.0 \% \pm 3.5 \%)$ (Figure 3A); while biochar amendment resulted in a small amount of PHE, FLA, and PYR loss compared to the control, of $7.2 \%, 2.8 \%$ and $13.2 \%$, respectively. In contrast, the rice straw biochar inoculated with $M$. gilvum cells exhibited the highest removal ability. Specifically, losses of PHE, FLA, and PYR, within 18 days, were $62.6 \pm 3.2 \%, 52.1 \pm 2.3 \%$, and $62.1 \pm 0.9 \%$, respectively, or compared to the control, $58.6 \%, 49.9 \%$, and $61.6 \%$, respectively. In comparison, free $M$. gilvum cells resulted in 43.3\%, 4.1\%, and 19.2\% losses of PHE, FLA, and PYR when compared to the control. Thus, biochar inoculated with M. gilvum cells resulted in $15.5 \%$ (PHE), $45.5 \%$ (FLA), and $42.6 \%$ (PYR) more degradation than just the free M. gilvum cells, at 18 days of incubation.

Changes in PHE, FLA, and PYR concentrations in the presence of $20 \mathrm{mg} \mathrm{g}^{-1}$ Brij 30 are presented in Figure 3B and Table S4. The surfactant, on its own, or in the presence 
of the biochar or free cells amendment, enhanced biodegradation of PHE, FLA and

342 PYR compared to the treatments without surfactant. However, for the inoculated

343 biochar amendments, the degradation assays with surfactant showed reduced

344 biodegradation compared to assays without surfactant (Figure 3). Specifically, for

345 treatments containing inoculated biochar, the degradation for PHE, FLA, and PYR,

346 decreased in the presence of surfactant by $10.5 \%, 13.3 \%$, and $23.6 \%$, respectively, when

347 compared to the surfactant-free treatments amended with the inoculated biochar. Thus,

348 while the surfactant enhanced biodegradation in the presence of the free microbes;

349 presumably on account of improved soil to solution mass transfer of PAHs (making

350 them more bioavailable), the surfactant was effective in impeding onward mass transfer

351 of PAHs to the biochar and their subsequent degradation by the M. gilvum cells.

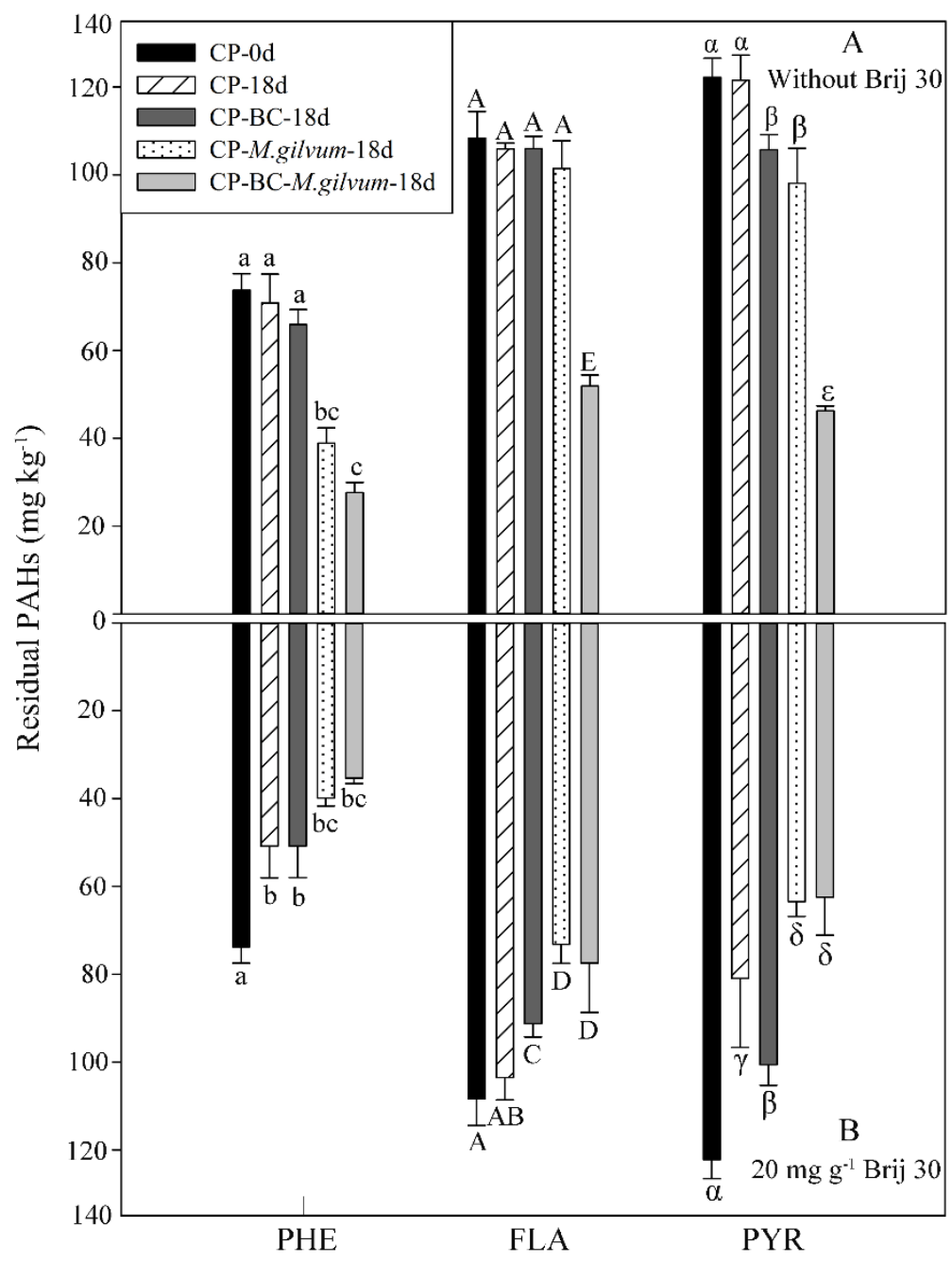


Figure 3. Residual phenanthrene (PHE), fluoranthene (FLA), and pyrene (PYR) concentrations in coke plant soil in the absence of Brij 30 (panel A) and presence of Brij 30 (panel B) while incubated in a mixed-media solution, comparing the initial concentration (CP-0d), with concentrations after 18 days following natural removal with no amendment (CP-18d), biochar-only amendment (CP-BC-18d), M. gilvum free cells amendment (CP-M. gilvum-18d), and biochar containing immobilized M. gilvum amendment (CP-BC-M. gilvium-18d) inoculation. Error bars represent the standard deviation $(n=3)$. Different letters indicate the mean difference is significant between treatments at the 0.05 level.

\subsection{Abundance Monitoring of M. gilvum in CP Soil with Different Treatments}

The change in M. gilvum cell numbers in the CP soil with different treatments at day 0 and day 18 were monitored by Taqman PCR assays, targeting the PAH-degrading mycobacteria nidA dioxygenase gene. The indigenous nidA copies in $\mathrm{CP}$ soil was $2.5 \times 10^{7} \pm 3.4 \times 10^{6}$ copies $/ \mathrm{g}_{\mathrm{dw}}$ soil, and the initial inoculation of free and biocharimmobilized cells increased nidA copies to $1.5 \times 10^{10} \pm 1.8 \times 10^{9}$ and $4.9 \times 10^{9} \pm 1 \times$ $10^{8}$ copies $/ \mathrm{g}_{\mathrm{dw}}$ soil (i.e. by factors of 622 and 288) respectively (Figure 4). Evidently, fewer M. gilvum cells were introduced to the treatments via the inoculated biochar amendment than the free cell addition, due to incomplete immobilization or biomass loss during the inoculation process. Figure 4 shows that, after 18-days of incubation, the nidA copies in the CP, Brij 30, and biochar amended soil was approximately 1.7 to 3.6 greater than those observed on day 0 , but no significant difference in nidA copies among these treatments $(\mathrm{P}>0.05)$ was observed. However, in the case of free-cell and biochar-inoculated $M$. gilvum treatments, nidA copies all decreased at day 18 to about $60 \%$ of the day 0 numbers (down to $5.9 \times 10^{9} \pm 5.7 \times 10^{8}, 1.9 \times 10^{9} \pm 6.8 \times 10^{8}$ copies $/ \mathrm{g}_{\mathrm{dw}}$ soil, respectively). At day 18, nidA copies on the inoculate-biochar amended soils remained lower than the free cell inoculations $(\mathrm{P}<0.01)$. The presence of $20 \mathrm{mg} \mathrm{g}^{-1}$ Brij $30 \mathrm{had}$ little influence on nidA copies for each of these two treatments (both $\mathrm{P}>0.05$ for free cell treatment and inoculated-biochar treatment). 


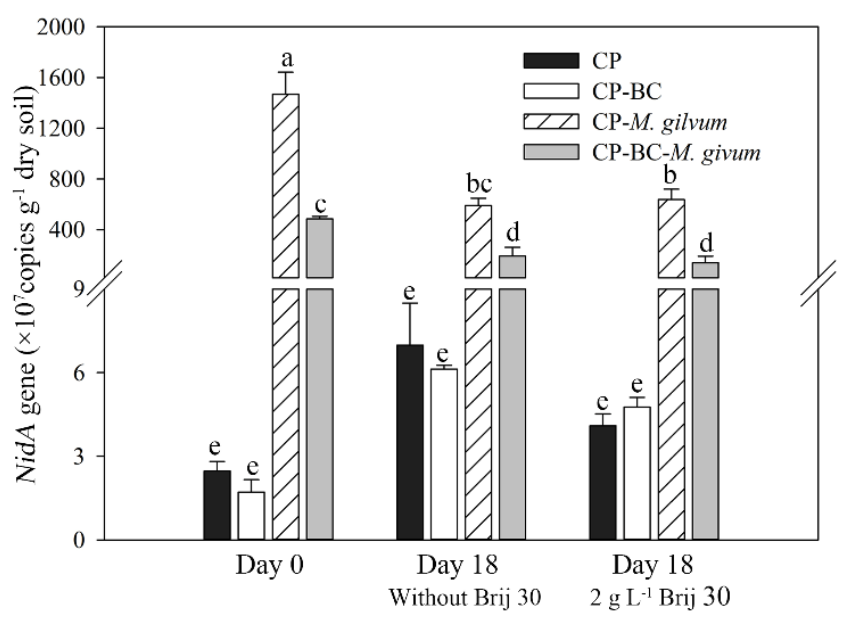

Figure 4. NidA copies in CP soil with different treatments at day 0 and day 18 , including natural removal with no amendments (CP-0d and $\mathrm{CP}-18 \mathrm{~d})$, biochar-only amendment (CP-BC-0d and CP-BC-18d), M. gilvum free cells amendment (CP $-M$. gilvum-0d and $\mathrm{CP}-M$. gilvum-18d), and biochar containing immobilized M. gilvum amendment (CP-BC-M. gilvum-0d and CP-BC-M.gilvum-18d). Different lower-case letters indicate the mean is significantly different between treatments at the 0.05 level.

\section{Discussion}

\subsection{Immobilization of M. gilvum on biochar}

SEM images and nidA copies presented in Figures 1 and 2 highlight the potential for biochar to provide a suitable habitat for microbial colonization (Saito 1990, Pietikäinen, Kiikkilä et al. 2000, Thies and Rillig 2009). Previous authors have proposed that two stages are involved in the immobilization of microbes on biochar (Klein and Ziehr 1990); the initial stage being adsorption of microbes onto biochars, which could be interpreted by the Derjaguin-Landau-Verwey-Overbeek (DLVO) theory of colloid stability (Hermansson 1999), and the second stage being biofilm formation. The accumulated biomass on biochar has been previously related to specific intrinsic properties of biochar, which vary significantly based on the preparation temperature and feedstock of bioochar (Tang, Zhu et al. 2013). In particular, pore size distribution, pore volume, surface area and surface properties (hydrophobicity, metallic oxides and functional groups) of chars, are critical parameters that affect the ability of biochar to 
serve as carrier for introducing bacteria to soils (Messing and Oppermann 1979, Rivera - Utrilla, Bautista - Toledo et al. 2001, Yamamoto, Nakakoshi et al. 2001, Upadhyayula, Deng et al. 2009, Hale, Luth et al. 2015). Messing et. al found that pore size distribution governed the optimum loading of bacteria, and that the maximum accumulation of stable biomass occurred when the pore diameters were in the range of one to five times the major dimension of the bacteria (Messing and Oppermann 1979). The existence of such pores within the rice straw biochar was evident in the SEM images (Figure S1(A)). The microbial adsorption capacity of chars has also been commonly observed to increase with the specific surface area, surface hydrophobicity and the amount of macropores (Krisdhasima, McGuire et al. 1992, Krisdhasima, Vinaraphong et al. 1993, Rivera - Utrilla, Bautista - Toledo et al. 2001). Metallic oxides and oxygen functional groups on the surface of chars are excellent adsorbents of microbes and thereby will increase the accumulation biomass (Rivera - Utrilla, Bautista - Toledo et al. 2001, Upadhyayula, Deng et al. 2009). Modification of AC with cations of $\mathrm{Fe}^{3+}, \mathrm{Ca}^{2+}, \mathrm{Mg}^{2+}$, respectively, has been found to lead to $87.8 \%, 54.7 \%$ and $24.8 \%$ increases in the microbial biomass accumulation (Rivera - Utrilla, Bautista Toledo et al. 2001). While the development of inoculant after incorperation into soil is more closely associated with the physical features of biochar, including surface area, pore opening diameter and water-filled pore spaces, which might play a significant role in protecting pre-immobilized colonies from predation (Hale, Luth et al. 2015).

On the other hand, microbes in themselves are expected to play a role in cell immobilization on biochar, particularly the surface hydrophobicity $(\mathrm{CSH})$ of cells, as hydrophobic bacteria are favorably attached to abiotic/hydrophobic surfaces (Krasowska and Sigler 2014). Genus of Mycobacterium has been reported to have extremely hydrophobic cell envelops (Hartmans, de Bont et al. 2006). Overall, 
hydrophobic areas of the right pore size therefore likely serve as centers for clustering of M. gilvum cells and biofilm, and the large surface area and pore volume (BET surface $68.06 \mathrm{~m}^{2} \mathrm{~g}^{-1}$, pore volume $0.17 \mathrm{~cm}^{3} \mathrm{~g}^{-1}$ ) support the potential for successful M. gilvum cell immobilization (Bastiaens, Springael et al. 2000, Uyttebroek, Breugelmans et al. 2006).

\subsection{PAH degradation after immobilization of M. gilvum cells on biochar}

PAH degradation depends on environmental conditions, the number and type of microorganisms, as well as the properties and chemical structure of the compound being degraded (Haritash and Kaushik 2009). The lower nidA copies detected in the biocharinoculated cell treatment compared to the free cell treatment, which underwent more biodegradation in $\mathrm{CP}$ soil, indicates that increased cell numbers alone is not the driver of increased PAH biodegradation (Figures $3 \& 4$ ). The aqueous concentrations of PHE, FLA, and PYR after 18 days (Figure S4, panel A, SI) were similar in all treatments (without surfactant). This indicates that neither the presence of biochar nor M. gilvum cells significantly affected the aqueous concentration of PAHs (based on the quantification method used).

Other researchers have reported increased PAH biodegradation is related to the increased presence of certain sorbing matrices (Ortega-Calvo and Saiz-Jimenez 1998, Uyttebroek, Ortega-Calvo et al. 2006, Mayer, Fernqvist et al. 2007, Smith, Thullner et al. 2009). Uyttebroek and co-workers observed the final degradation extent of PHE in porous synthetic amberlite sorbent (IRC50) (53-62\%) was significantly higher than in absence of IRC50 (18-52\%) for all tested Mycobacterium strains; these results were interpreted as preferential degradation of PHE sorbed to IRC50 (Uyttebroek, Ortega-

Calvo et al. 2006). Furthermore, in the presence of IRC50, the maximum PHE 
mineralization rate (1.1-1.9 $\left.\mathrm{ng} \mathrm{ml}^{-1} \mathrm{~h}^{-1}\right)$ for all tested Mycobacteria were significantly

452

453 higher than the initial abiotic desorption rate $\left(0.2 \mathrm{ng} \mathrm{ml}^{-1} \mathrm{~h}^{-1}\right)$, suggesting that the bacterial utilized sorbed PHE with a higher rate than can be explained by abiotic desorption. Smith et al. observed sorption to humic acids increased degradation rates of PHE by factors up to 4.8 while leaving the water-dissolved PAH concentrations unchanged; proposing that additional humic acids-mediated transport was the responsible mechanism for enhanced PHE degradation (Smith, Thullner et al. 2009). Ortaga-Calvo and co-workers detected a shortened biodegradation acclimation phase and higher PHE mineralization rates in the presence of $100 \mu \mathrm{g} \mathrm{ml}^{-1}$ humic acid and 10 $\mathrm{g} \mathrm{L}^{-1}$ clay, both separately and in combination. They proposed that the enrichment of PHE and degrading cells on these soil components resulted in the improved utilization of PHE, and thus the total degradation was increased (Ortega-Calvo and Saiz-Jimenez 1998). These studies all indicate that both dissolved and solid sorbing matrices can facilitate PAH degradation by assisting in PAH mass transfer to degrading cells in a sorbent-amended system. We propose, in our system, that biochar may act in a similar way, playing a role in the supply of PAHs to sorbed M. gilvum cells.

Reduced PAH degradation by immobilized bacteria, in the presence of surfactant Brij 30 (Figure 3), further supports this mechanism. The toxicity of Brij 30 to M. gilvum cells can be excluded as the reason of reduced PAH loss, because i) in our study increased biodegradation was exhibited in other parallel treatments in the presence of Brij 30 (Figure 3), without notable changes in nidA copies; and ii) Brij 30 exhibits low microbial toxicity below $1.5 \mathrm{~g} \mathrm{~L}^{-1}$ (Kim, Park et al. 2001). Several studies have reported that organic contaminant adsorption onto ACs, and especially biochars, would be considerably restrained by surfactants (Ahn, Kim et al. 2008, Han, Liu et al. 2013). Ahn et al. found that the amount of PHE adsorbed onto AC and biochar substantially 
decreased in the presence of Brij 30, likely due to the high solubilizing ability of the Brij 30 surfactant (Ahn, Kim et al. 2008). Aqueous concentrations for PHE, FLA, and PYR in the Brij 30 amended system after 18 days, were generally greater by a factor of 8.3, 6.1 and 4.5, respectively (SI-Figure S4B, Table S5). Thus, the lower biodegradation observed in the Brij 30 systems is likely due to less sorption to both biochar and $M$. gilvum cells.

\subsection{Effective biodegradation of biochar-sorbed PAHs}

Biodegradation of sorbed PAHs has been reported by various pathways, in particular: (1) high-affinity uptake systems of degrading cells (Wick, Springael et al. 2001, Wick, De Munain et al. 2002), (2) adhesion/biofilm formation on sorbed-PAHs (Wick, De Munain et al. 2002, Johnsen and Karlson 2004, Uyttebroek, Breugelmans et al. 2006), and (3) biosurfactant excretion (Deziel, Paquette et al. 1996, Willumsen and Karlson 1996).

M. gilvum is one of the most effective PAH-degrading Mycobacteria (Kim, Kweon et al. 2010). This genus has been reported to have a high specific substrate affinity towards PAHs, well adapted to degrade sorbed PAHs (Guerin and Boyd 1992, Bastiaens, Springael et al. 2000, Derz, Klinner et al. 2004, Hartmans, de Bont et al. 2006, Uyttebroek, Ortega-Calvo et al. 2006). Mycobacteria have complex and extremely hydrophobic rigid cell envelopes, rich in mycolic acids (Hartmans, de Bont et al. 2006), which are important for the interaction with or uptake of hydrophobic compounds (Rijnaarts, Norde et al. 1992). Particularly, several studies reported that the mycolic acid wall monolayer in Mycobacteria forms a hydrophobic surface, which may enhance the specific substrate efficiency of PAHs (Bastiaens, Springael et al. 2000, Wick, De Munain et al. 2002, Wick, Pasche et al. 2003). Concentrations of PAHs could be 
effectively reduced at the $M$. gilvum cells surface; hence, creating a steep concentration gradient between cell surface and biochar-binding PAHs, which could lead to continuously uptake-driven desorption. In the case of biochar-inoculated with $M$. gilvum cells, biochar acts as an effective sink, to increase PAH flux more than just the freely suspended M. gilvum cells.

M. gilvum cells may also experience advantages associated with sorbed-PAHs as a substrate (Wick, De Munain et al. 2002, Uyttebroek, Breugelmans et al. 2006). Our durability test data showed appreciable $M$. gilvum biomass was steadily maintained on rice straw biochar (approximately $7.0 \times 10^{10}$ copies $/ g_{d w}$ biochar) on the $18^{\text {th }}$ day after immobilization (Figure 2). The enrichment of PAHs on the biochar, as a substrate, not only increases contact opportunity with PAHs, it also increases concentration gradients between PAHs sorbed to biochar surfaces and cell-surfaces across short distances, as was observed elsewhere for 3-chlorodibenzofuran (Harms and Zehnder 1995). Mayer et. al reported that the direct contact between a digesting gut and sediment matrix resulted in a 230 times increase in the PHE mass transfer coefficient (Mayer, Fernqvist et al. 2007), indicating that efficient contact between M. gilvum cells and PAHs on biochar would be beneficial to the PAH mineralization.

An additional explanation to account for the quicker degradation kinetics is biofilm formation on biochar. Wick et al. reported the attachment and biofilm formation of Mycobacterium sp. LB501T on solid anthracene surfaces using SEM (Wick, Ruiz et al. 2002). In our study, biofilm flocs and EPS on the surface of biochar immobilized $M$. gilvum cells were commonly recorded during SEM imaging (Figure 1 (E) \& (F)). Biofilm and EPS formation are conducive to the mass transfer or substrate uptake of PAHs, and the biofilm from the Mycobacterium is likely unique to other cell-interface 
process occurring in the $\mathrm{CP}$ soil. On the other hand, biochar in itself can harbor both hydrophilic and hydrophobic functional groups (SI, Table S2), particularly, comparably higher surface basic (hydrophobic) groups in rice straw biochar would be advantageous for the adsorption of hydrophobic organic contaminants. Thus, several plausible mechanisms may explain why $M$. gilvum cells immobilized on biochar degraded PAHs more rapidly than free $M$. gilvum cells.

\section{Conclusions}

Indigenous PAH-degrading microbes (M. gilvum) were immobilized on rice straw biochar, with high abundance and durability. The M. gilvum-biochar composite showed superior degradation capacity for phenanthrene, fluoranthene and pyrene, with a $62.6 \pm 3.2 \%, 52.1 \pm 2.3 \%$ and $62.1 \pm 0.9 \%$ of removal from the historically contaminated soil, respectively. It was proposed that the improved remediation was attributed to the targeted degradation of biochar sorbed PAHs. Biochar in itself was a carbonaceous 'sink' both for pollutants and degrading cells. Such simultaneous enrichment provided a means to reduce pollutants and degrading microbes being spatial isolated from one and other. The proposed mechanism was further supported by observing a significantly decrease in the degradation of PAHs in a biochar- $M$. gilvum composite system when the surfactant Brij 30 was added to impede the PAH mass transfer to biochar. Further research to investigate the delivery of PAHs towards the biochar surfaces could provide better understanding of the underlying mechanisms of this enhanced PAH-degradation soil system. Whether similar results would occur in the field as observed in this labstudy is uncertain, and would need to be investigated as a follow-up study. 
546 Devolopment of inoculant on biochar is also expected to be investigated for a better

547 understanding of biochar-microbe interactions.

\section{Supporting Information.}

549 Additional methods, data tables and figures can be founded in the Supporting 550 Information.

\section{Acknowledgment}

552 This research was financially supported by the National Natural Science Foundation 553 of China (Grant No. 41271324) and the National High-Tech R\&D Program of China 554 (863 Program) (Grant No. 2013AA06A211).

555 


\section{References}

Accardi-Dey, A. and P. M. Gschwend (2003). "Reinterpreting literature sorption data considering both absorption into organic carbon and adsorption onto black carbon." Environmental Science \& Technology 37(1): 99-106.

Ahn, C., Y. Kim, S. Woo and J. Park (2008). "Soil washing using various nonionic surfactants and their recovery by selective adsorption with activated carbon." Journal of Hazardous Materials 154(1): 153-160.

Ahn, S., D. Werner and R. G. Luthy (2008). "Modeling PAH mass transfer in a slurry of contaminated soil or sediment amended with organic sorbents." Water research 42(12): 2931-2942. Arp, H. P. H., S. Lundstedt, S. Josefsson, G. Cornelissen, A. Enell, A.-S. Allard and D. B. Kleja (2014). "Native oxy-PAHs, N-PACs, and PAHs in historically contaminated soils from Sweden, Belgium, and France: Their soil-porewater partitioning behavior, bioaccumulation in Enchytraeus crypticus, and bioavailability." Environmental science \& technology 48(19): 11187-11195.

Bakker, M. I., B. Casado, J. W. Koerselman, J. Tolls and C. KollÃ $q f f e l$ (2000). "Polycyclic aromatic hydrocarbons in soil and plant samples from the vicinity of an oil refinery." Science of the Total Environment 263(1): 91-100.

Bastiaens, L., D. Springael, P. Wattiau, H. Harms, H. Verachtert and L. Diels (2000). "Isolation of adherent polycyclic aromatic hydrocarbon (PAH)-degrading bacteria using PAH-sorbing carriers." Applied and Environmental Microbiology 66(5): 1834-1843.

Baussant, T., S. Sanni, G. Jonsson, A. Skadsheim and J. F. BøRSETH (2001). "Bioaccumulation of polycyclic aromatic compounds: 1 . Bioconcentration in two marine species and in semipermeable membrane devices during chronic exposure to dispersed crude oil." Environmental Toxicology and Chemistry 20(6): 1175-1184.

Beesley, L., E. Moreno-Jiménez, J. L. Gomez-Eyles, E. Harris, B. Robinson and T. Sizmur (2011). "A review of biochars' potential role in the remediation, revegetation and restoration of contaminated soils." Environmental pollution 159(12): 3269-3282.

Cho, Y.-M., D. Werner, Y. Choi and R. G. Luthy (2012). "Long-term monitoring and modeling of the mass transfer of polychlorinated biphenyls in sediment following pilot-scale in-situ amendment with activated carbon." Journal of contaminant hydrology 129: 25-37.

Cornelissen, G., G. D. Breedveld, S. Kalaitzidis, K. Christanis, A. Kibsgaard and A. M. Oen (2006). "Strong sorption of native PAHs to pyrogenic and unburned carbonaceous geosorbents in sediments." Environmental science \& technology 40(4): 1197-1203.

Cornelissen, G. and Ö. Gustafsson (2004). "Sorption of phenanthrene to environmental black carbon in sediment with and without organic matter and native sorbates." Environmental science \& technology 38(1): 148-155.

DeBruyn, J. M., C. S. Chewning and G. S. Sayler (2007). "Comparative quantitative prevalence of Mycobacteria and functionally abundant nidA, nahAc, and nagAc dioxygenase genes in coal tar contaminated sediments." Environmental science \& technology 41(15): 5426-5432.

Derz, K., U. Klinner, I. Schuphan, E. Stackebrandt and R. M. Kroppenstedt (2004). "Mycobacterium pyrenivorans sp. nov., a novel polycyclic-aromatic-hydrocarbon-degrading species." International journal of systematic and evolutionary microbiology 54(6): 2313-2317. 
Deziel, E., G. Paquette, R. Villemur, F. Lepine and J. Bisaillon (1996). "Biosurfactant production by a soil pseudomonas strain growing on polycyclic aromatic hydrocarbons." Applied and environmental microbiology 62(6): 1908-1912.

Fabbri, D., A. G. Rombolà, C. Torri and K. A. Spokas (2013). "Determination of polycyclic aromatic hydrocarbons in biochar and biochar amended soil." Journal of Analytical and Applied Pyrolysis 103: 60-67.

Gan, S., E. Lau and H. Ng (2009). "Remediation of soils contaminated with polycyclic aromatic hydrocarbons (PAHs)." Journal of Hazardous Materials 172(2): 532-549.

Ghosh, U., R. G. Luthy, G. Cornelissen, D. Werner and C. A. Menzie (2011). "In-situ sorbent amendments: a new direction in contaminated sediment management." Environmental Science \& Technology 45(4): 1163-1168.

Goldman, R., L. Enewold, E. Pellizzari, J. B. Beach, E. D. Bowman, S. S. Krishnan and P. G. Shields (2001). "Smoking increases carcinogenic polycyclic aromatic hydrocarbons in human lung tissue." Cancer research 61(17): 6367-6371.

Gomez-Eyles, J. L., C. Yupanqui, B. Beckingham, G. Riedel, C. Gilmour and U. Ghosh (2013). "Evaluation of biochars and activated carbons for in situ remediation of sediments impacted with organics, mercury, and methylmercury." Environmental science \& technology 47(23): 1372113729 .

Guerin, W. F. and S. A. Boyd (1992). "Differential bioavailability of soil-sorbed naphthalene to two bacterial species." Applied and Environmental Microbiology 58(4): 1142-1152.

Haftka, J. J., J. R. Parsons, H. A. Govers and J. J. Ortega-Calvo (2008). "Enhanced kinetics of solidphase microextraction and biodegradation of polycyclic aromatic hydrocarbons in the presence of dissolved organic matter." Environmental Toxicology and Chemistry 27(7): 1526-1532.

Hale, L., M. Luth and D. Crowley (2015). "Biochar characteristics relate to its utility as an alternative soil inoculum carrier to peat and vermiculite." Soil Biology and Biochemistry 81: 228235.

Hale, L., M. Luth, R. Kenney and D. Crowley (2014). "Evaluation of pinewood biochar as a carrier of bacterial strain Enterobacter cloacae UW5 for soil inoculation." Applied Soil Ecology 84: 192199.

Hale, S., K. Hanley, J. Lehmann, A. Zimmerman and G. Cornelissen (2011). "Effects of chemical, biological, and physical aging as well as soil addition on the sorption of pyrene to activated carbon and biochar." Environmental science \& technology 45(24): 10445-10453.

Han, D., X. Liu, G. Zhang, K. Sun and Y. Jiao (2013). "Effect of cationic surfactant on pentachlorophenol sorption by sediment, active carbon and biochar." Fresenius Environmental Bulletin 22(4 B): 1280-1286.

Haritash, A. and C. Kaushik (2009). "Biodegradation aspects of polycyclic aromatic hydrocarbons (PAHs): a review." Journal of hazardous materials 169(1): 1-15.

Harms, H. and A. Zehnder (1995). "Bioavailability of sorbed 3-chlorodibenzofuran." Applied and environmental microbiology 61(1): 27-33.

Hartmans, S., J. A. de Bont and E. Stackebrandt (2006). The Genus Mycobacterium--Nonmedical. The Prokaryotes, Springer: 889-918.

Hermansson, M. (1999). "The DLVO theory in microbial adhesion." Colloids and Surfaces B: Biointerfaces 14(1): 105-119. 
Johnsen, A. and U. Karlson (2004). "Evaluation of bacterial strategies to promote the bioavailability of polycyclic aromatic hydrocarbons." Applied microbiology and biotechnology 63(4): 452-459. Karcz, J., T. Bernas, A. Nowak, E. Talik and A. Woznica (2012). "Application of lyophilization to prepare the nitrifying bacterial biofilm for imaging with scanning electron microscopy." Scanning 34(1): 26-36.

Kim, I. S., J.-S. Park and K.-W. Kim (2001). "Enhanced biodegradation of polycyclic aromatic hydrocarbons using nonionic surfactants in soil slurry." Applied Geochemistry 16(11): 1419-1428. Kim, S.-J., O. Kweon and C. Cerniglia (2010). Degradation of polycyclic aromatic hydrocarbons by Mycobacterium strains. Handbook of hydrocarbon and lipid microbiology, Springer: 1865-1879. Klein, J. and H. Ziehr (1990). "Immobilization of microbial cells by adsorption." Journal of biotechnology 16(1): 1-15.

Krasowska, A. and K. Sigler (2014). "How microorganisms use hydrophobicity and what does this mean for human needs?" Frontiers in cellular and infection microbiology 4.

Krisdhasima, V., J. McGuire and R. Sproull (1992). "A one-film-model ellipsometry program for the simultaneous calculation of protein film thickness and refractive index." Surface and interface analysis 18(6): 453-456.

Krisdhasima, V., P. Vinaraphong and J. McGuire (1993). "Adsorption kinetics and elutability of $\alpha$ lactalbumin, $\beta$-casein, $\beta$-lactoglobulin, and bovine serum albumin at hydrophobic and hydrophilic interfaces." Journal of colloid and interface science 161(2): 325-334.

Latawiec, A., A. Swindell, P. Simmons and B. Reid (2010). "Bringing bioavailability into contaminated land decision making: the way forward?" Critical Reviews in Environmental Science and Technology 41(1): 52-77.

Lehmann, J. (2007). "A handful of carbon." Nature 447(7141): 143-144.

Lehmann, J. and S. Joseph (2012). Biochar for environmental management: science and technology, Routledge.

Lehmann, J. and S. Joseph (2015). Biochar for environmental management: science, technology and implementation, Routledge.

Leite, D., F. Balieiro, C. Pires, B. Madari, A. Rosado, H. Coutinho and R. Peixoto (2014). "Comparison of DNA extraction protocols for microbial communities from soil treated with biochar." Brazilian Journal of Microbiology 45(1): 175-183.

Lin, C.-W., C.-H. Wu, W.-T. Huang and S.-L. Tsai (2015). "Evaluation of different cellimmobilization strategies for simultaneous distillery wastewater treatment and electricity generation in microbial fuel cells." Fuel 144: 1-8.

Lin, Q., W. Donghui and W. Jianlong (2010). "Biodegradation of pyridine by Paracoccus sp. KT-5 immobilized on bamboo-based activated carbon." Bioresource technology 101(14): 5229-5234.

Liu, L., P. Chen, M. Sun, G. Shen and G. Shang (2015). "Effect of biochar amendment on PAH dissipation and indigenous degradation bacteria in contaminated soil." Journal of Soils and Sediments 15(2): 313-322.

Mastrangelo, G., E. Fadda and V. Marzia (1996). "Polycyclic aromatic hydrocarbons and cancer in man." Environmental health perspectives 104(11): 1166.

Mayer, P., M. M. Fernqvist, P. S. Christensen, U. Karlson and S. Trapp (2007). "Enhanced diffusion of polycyclic aromatic hydrocarbons in artificial and natural aqueous solutions." Environmental science \& technology 41(17): 6148-6155. 
Messing, R. and R. Oppermann (1979). "Pore dimensions for accumulating biomass. I. Microbes that reproduce by fission or by budding." Biotechnology and Bioengineering 21(1): 49-58.

Morsen, A. and H.-J. Rehm (1990). "Degradation of phenol by a defined mixed culture immobilized by adsorption on activated carbon and sintered glass." Applied Microbiology and Biotechnology 33(2): 206-212.

Oleszczuk, P., S. E. Hale, J. Lehmann and G. Cornelissen (2012). "Activated carbon and biochar amendments decrease pore-water concentrations of polycyclic aromatic hydrocarbons (PAHs) in sewage sludge." Bioresource technology 111: 84-91.

Ortega-Calvo, J.-J., J. Harmsen, J. R. Parsons, K. T. Semple, M. D. Aitken, C. Ajao, C. Eadsforth, M. Galay-Burgos, R. Naidu and R. Oliver (2015). "From bioavailability science to regulation of organic chemicals." Environmental science \& technology 49(17): 10255-10264.

Ortega-Calvo, J.-J. and C. Saiz-Jimenez (1998). "Effect of humic fractions and clay on biodegradation of phenanthrene by a Pseudomonas fluorescens strain isolated from soil." Applied and environmental microbiology 64(8): 3123-3126.

Pietikäinen, J., O. Kiikkilä and H. Fritze (2000). "Charcoal as a habitat for microbes and its effect on the microbial community of the underlying humus." Oikos 89(2): 231-242.

Quilliam, R. S., K. A. Marsden, C. Gertler, J. Rousk, T. H. DeLuca and D. L. Jones (2012). "Nutrient dynamics, microbial growth and weed emergence in biochar amended soil are influenced by time since application and reapplication rate." Agriculture, Ecosystems \& Environment 158: 192-199.

Rhodes, A. H., A. Carlin and K. T. Semple (2008). "Impact of black carbon in the extraction and mineralization of phenanthrene in soil." Environmental Science \& Technology 42(3): 740-745.

Rhodes, A. H., L. E. McAllister, R. Chen and K. T. Semple (2010). "Impact of activated charcoal on the mineralisation of ${ }^{14} \mathrm{C}$-phenanthrene in soils." Chemosphere 79(4): 463-469.

Rijnaarts, H., W. Norde, J. Lyklema and A. Zehnder (1992). "Effect of substrate adsorption an microbial adhesion on bacterial growth and activity."

Rivera-Utrilla, J., I. Bautista-Toledo, M. A. Ferro-García and C. Moreno-Castilla (2001). "Activated carbon surface modifications by adsorption of bacteria and their effect on aqueous lead adsorption." Journal of Chemical Technology and biotechnology 76(12): 1209-1215.

Saito, M. (1990). "Charcoal as a micro-habitat for VA mycorrhizal fungi, and its practical implication." Agriculture, Ecosystems \& Environment 29(1): 341-344.

Samanta, S. K., O. V. Singh and R. K. Jain (2002). "Polycyclic aromatic hydrocarbons: environmental pollution and bioremediation." TRENDS in Biotechnology 20(6): 243-248.

Smith, K. E., M. Thullner, L. Y. Wick and H. Harms (2009). "Sorption to humic acids enhances polycyclic aromatic hydrocarbon biodegradation." Environmental science \& technology 43(19): 7205-7211.

Song, Z., S. R. Edwards and R. G. Burns (2006). "Treatment of naphthalene-2-sulfonic acid from tannery wastewater by a granular activated carbon fixed bed inoculated with bacterial isolates Arthrobacter globiformis and Comamonas testosteroni." Water research 40(3): 495-506.

Steinbeiss, S., G. Gleixner and M. Antonietti (2009). "Effect of biochar amendment on soil carbon balance and soil microbial activity." Soil Biology and Biochemistry 41(6): 1301-1310.

Tang, J., W. Zhu, R. Kookana and A. Katayama (2013). "Characteristics of biochar and its application in remediation of contaminated soil." Journal of bioscience and bioengineering 116(6): 653-659. 
Tang, L., X.-Y. Tang, Y.-G. Zhu, M.-H. Zheng and Q.-L. Miao (2005). "Contamination of polycyclic aromatic hydrocarbons (PAHs) in urban soils in Beijing, China." Environment international 31(6): 822-828.

Thies, J. E. and M. C. Rillig (2009). "Characteristics of biochar: biological properties." Biochar for environmental management: Science and technology: 85-105.

Upadhyayula, V. K., S. Deng, G. B. Smith and M. C. Mitchell (2009). "Adsorption of Bacillus subtilis on single-walled carbon nanotube aggregates, activated carbon and NanoCeramâ,,ф." Water research 43(1): 148-156.

Uyttebroek, M., P. Breugelmans, M. Janssen, P. Wattiau, B. Joffe, U. Karlson, J. J. Ortega-Calvo, L. Bastiaens, A. Ryngaert and M. Hausner (2006). "Distribution of the Mycobacterium community and polycyclic aromatic hydrocarbons (PAHs) among different size fractions of a long-term $\mathrm{PAH}^{-}$ contaminated soil." Environmental Microbiology 8(5): 836-847.

Uyttebroek, M., J.-J. Ortega-Calvo, P. Breugelmans and D. Springael (2006). "Comparison of mineralization of solid-sorbed phenanthrene by polycyclic aromatic hydrocarbon (PAH)-degrading Mycobacterium spp. and Sphingomonas spp." Applied microbiology and biotechnology 72(4): 829836.

Wagrowski, D. M. and R. A. Hites (1996). "Polycyclic aromatic hydrocarbon accumulation in urban, suburban, and rural vegetation." Environmental Science \& Technology 31(1): 279-282.

Werner, D., U. Ghosh and R. G. Luthy (2006). "Modeling polychlorinated biphenyl mass transfer after amendment of contaminated sediment with activated carbon." Environmental science \& technology 40(13): 4211-4218.

Wick, L., A. De Munain, D. Springael and H. Harms (2002). "Responses of Mycobacterium sp. LB501T to the low bioavailability of solid anthracene." Applied microbiology and biotechnology 58(3): 378-385.

Wick, L., D. Springael and H. Harms (2001). Bacterial strategies to improve the bioavailability of hydrophobic organic pollutants. Treatment of contaminated soil, Springer: 203-217.

Wick, L. Y., N. Pasche, S. M. Bernasconi, O. Pelz and H. Harms (2003). "Characterization of multiple-substrate utilization by anthracene-degrading Mycobacterium frederiksbergense LB501T." Applied and environmental microbiology 69(10): 6133-6142.

Wick, L. Y., d. M. A. Ruiz, D. Springael, H. Harms and M. A. De (2002). "Responses of Mycobacterium sp. LB501T to the low bioavailability of solid anthracene." Applied Microbiology and Biotechnology 58(5): 683-683.

Willumsen, P. A. and U. Karlson (1996). "Screening of bacteria, isolated from PAH-contaminated soils, for production of biosurfactants and bioemulsifiers." Biodegradation 7(5): 415-423.

Wu, W., M. Yang, Q. Feng, K. McGrouther, H. Wang, H. Lu and Y. Chen (2012). "Chemical characterization of rice straw-derived biochar for soil amendment." Biomass and Bioenergy 47: 268276.

Yamamoto, O., K. Nakakoshi, T. Sasamoto, H. Nakagawa and K. Miura (2001). "Adsorption and growth inhibition of bacteria on carbon materials containing zinc oxide." Carbon 39(11): 1643-1651. Zhu, H. and M. D. Aitken (2010). "Surfactant-enhanced desorption and biodegradation of polycyclic aromatic hydrocarbons in contaminated soil." Environmental science \& technology 44(19): 72607265 .

\section{Supporting Information}




\section{Enhanced biodegradation of PAHs in}

\section{historically contaminated soil by $M$. gilvum inoculated biochar cells}

Bijing Xiong, ${ }^{\dagger} \star \star$ Youchi Zhang, ${ }^{\dagger}$ Yanwei Hou ${ }^{\S}$ Hans Peter H. Arp, ${ }^{\prime \prime}$ Brian J. Reid, ${ }^{\dagger, \dagger}$ Chao Cai ${ }^{*}{ }^{\dagger}$

$\dagger$ Key Lab of Urban Environment and Health, Institute of Urban Environment, Chinese Academy of Sciences, Xiamen 361021, China

$\$$ University of Chinese Academy of Sciences, Beijing 100049, China

$\S$ Department of Environment Science and Engineering, Huaqiao University, Xiamen 361021, China

//Norwegian Geotechnical Institute (NGI), P.O. Box 3930, Ullevål Stadion, N-0806 Oslo, Norway

${ }^{\dagger}$ School of Environmental Sciences, University of East Anglia, Norwich, NR4 7TJ, UK

*Corresponding author e-mail: ccai@iue.ac.cn

${ }^{\#}$ These authors contributed equally to this work

Number of pages: 12

Number of tables:5

Number of figures:4

\section{S1. Supporting Methodology}

pH was measured in a suspension of soil/biochar and $0.01 \mathrm{M} \mathrm{CaCl}_{2}(1: 2.5)$. 
Total $\mathbf{C}, \mathbf{N}$ and $\mathbf{S}$ in soil, biochar were measured by dry combustion using a macroelementor (VarioMax CNS, Germany). Soil (400 mg) and biochar (300 mg) samples were processed using combustion temperature $(\mathrm{H} 1) 1140^{\circ} \mathrm{C}$, post combustion (H2) $800^{\circ} \mathrm{C}$ and reduction $(\mathrm{H} 3) 850^{\circ} \mathrm{C}$, while $\mathrm{He}$ flow was $680 \mathrm{ml} / \mathrm{min}$ as mentioned in the operational manual. Soil particle size was measured using the Mastersizer 2000 (Malvern Instruments Ltd, UK)

Soil organic matter (SOM) was determined by oxidation with potassium dichromatetitration with $\mathrm{FeSO}_{4}$.

Soil particle size distribution was measured using the micro-pipette method.(Miller and Miller 1987)

Selection of biochar pyrolysis temperature. Rice straw was pyrolized at $300^{\circ} \mathrm{C}, 400^{\circ} \mathrm{C}$, $500^{\circ} \mathrm{C}, 600^{\circ} \mathrm{C}$ to produce separate biochars. Characterization of these biochars showed that their specific surface area, pore volume and mesopore volume increased with an increase of pyrolysis temperature. Specifically, the specific surface area of biochar produced at $300^{\circ} \mathrm{C}, 400^{\circ} \mathrm{C}, 500^{\circ} \mathrm{C}, 600^{\circ} \mathrm{C}$ was $9.45,11.36,68.06$ and $76.14 \mathrm{~m}^{2} \mathrm{~g}^{-1}$, respectively; whereas for pore volume, it was $0.0114,0.0159,0.1732$ and $0.1862 \mathrm{~cm}^{3}$ $\mathrm{g}^{-1}$, respectively; and for the mesopore volume, it was $6.4,9.515 .7$ and $17.3 \mathrm{~m}^{2} \mathrm{~g}^{-1}$, respectively. However, biochar yield decreased substantially with an increase of pyrolysis temperature, with a yield of $42.23 \%, 35.52 \%, 34.23 \%$ and $25.94 \%$, respectively. Higher specific surface area, pore volume and mesopore volume are advantageous for bacterial adsorption. Considering these fetures of biochar prepared at $500^{\circ} \mathrm{C}$ and $600^{\circ} \mathrm{C}$ were similar, ultimately we selected pyrolysis temperature of $500^{\circ} \mathrm{C}$ 
for a higher yield of biochar.

The Brunauer-Emmett-Teller method of multiple points was employed for surface area calculation, while four data points, with relative pressures of 0.05 to 0.3 , were used to construct the monolayer adsorption capacity.

Ash content was determined by ASTM proximate analysis method for biochars (ASTM D1762-84, reapproved 2007). Detailedly, ash is determined as the residue after burning to constant weight at $750^{\circ} \mathrm{C}$.

The titration method proposed by Boehm (Boehm 2002) was used to estimate the number of oxygenated surface groups. Rice straw biochar $(0.5 \mathrm{~g})$ was respectively added with $25 \mathrm{ml}$ of the following solutions: $0.1 \mathrm{M} \mathrm{HCl}, 0.1 \mathrm{M} \mathrm{NaOH}, 0.1 \mathrm{M} \mathrm{Na}_{2} \mathrm{CO}_{3}$ and $0.1 \mathrm{M} \mathrm{NaHCO}_{3}$ in $50-\mathrm{ml}$ centrifuge tube. All solutions were then incubated on a roatary shaker at $200 \mathrm{r} \mathrm{min}^{-1}$ for $30 \mathrm{~min}$. After that solutions were equilibrated in a constant temperature incubator at $25^{\circ} \mathrm{C}$ for $24 \mathrm{~h}$. After the equilibration process, samples were filtered through the polycarbonate filter. A volume of $10 \mathrm{ml}$ of each solution obtained by the filtration process was transferred into 150 -ml flasks and diluted with 40-ml distilled water. A drop $(200 \mu \mathrm{l})$ of the indicator (phenothalin/methyl red) was added to each of the test flask which were subsequently stirred at the vortex. Then the all prepared solutions were used to the acid-base titration by $0.1 \mathrm{M} \mathrm{NaOH}$ or $0.1 \mathrm{M}$ $\mathrm{HCl}$.

PAH analysis in CP soil. PAHs in CP soil with different treatments were extracted using a previously established method for quantifying the 16 US EPA PAHs in biochars

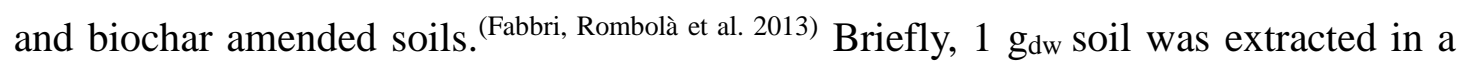


cellulose thimble in $200 \mathrm{ml}$ of acetone:cyclohexane $(1: 1, \mathrm{v} / \mathrm{v})$ in a Soxhlet for $48 \mathrm{~h}$. Twenty-five $\mu$ l of surrogate standard mix at a concentration of $400 \mu \mathrm{g} \mathrm{ml}^{-1}$ were added prior to extraction. Soxhlet extracts were concentrated to approximately $1 \mathrm{ml}$ by rotary vacuum evaporation at $39^{\circ} \mathrm{C}$. Then $15 \mathrm{ml}$ of hexane were added and further concentrated to $1 \mathrm{ml}$ to accomplish the exchange of solvent before clean-up, following the US EPA Method 3630C, and thereafter exchanged back to hexane and diluted by a factor of 100 (to quantify the abundant PAHs in the CP soil). Fifty $\mu 1$ of internal standard hexamethylbenzene $\left(10 \mu \mathrm{g} \mathrm{ml}^{-1}\right.$ in acetone) were added before analysis by gas chromatography-mass spectroscopy. 


\section{$\underline{\text { S2. Supplementary Data Tables }}$}

Table S1 Characteristics of biochar derived from different feedstocks

\begin{tabular}{|c|c|c|c|c|c|c|}
\hline \multirow{2}{*}{ Biochar } & \multicolumn{2}{|c|}{$\begin{array}{l}\text { Elemental } \\
\text { analysis (\%) }\end{array}$} & \multirow{2}{*}{$\begin{array}{l}\text { Ash } \\
\text { content } \\
(\%)\end{array}$} & \multirow[t]{2}{*}{$\mathrm{pH}$} & \multirow[t]{2}{*}{$\begin{array}{c}\text { BET SSA } \\
\left(\mathrm{m}^{2} \cdot \mathrm{g}^{-1}\right)\end{array}$} & \multirow{2}{*}{$\begin{array}{l}\text { Pore } \\
\text { volume } \\
\left(\mathrm{cm}^{3} \cdot \mathrm{g}^{-1}\right)\end{array}$} \\
\hline & $\mathrm{C}$ & $\mathrm{N}$ & & & & \\
\hline Rice straw biochar & 48.6 & 1.7 & 29.3 & 10.14 & 68.06 & 0.173 \\
\hline Sewage sludge biochar & 27.1 & 3.4 & 70.4 & 10.00 & 5.42 & 0.014 \\
\hline Pig manure biochar & 63.9 & 4.9 & 70.4 & 9.52 & 10.48 & 0.020 \\
\hline
\end{tabular}

Table S2 Results of Boehm titrations of different biochars

\begin{tabular}{lccccc}
\hline & \multicolumn{2}{c}{ Acidic surface functions $\left(\mathrm{mmol} \mathrm{g}^{-1}\right)$} & & $\begin{array}{c}\text { Basic groups } \\
\left(\mathrm{mmol} \mathrm{g}^{-1}\right)\end{array}$ & $\begin{array}{c}\text { Total surface } \\
\text { oxides }\left(\mathrm{mmol} \mathrm{g}^{-1}\right)\end{array}$ \\
\cline { 2 - 4 } & $\begin{array}{c}\text { Carboxyl } \\
\text { groups }\end{array}$ & Lactones & $\begin{array}{c}\text { Hydroxyl group } \\
\text { of phenolic } \\
\text { character }\end{array}$ & & \\
\hline Rice straw biochar & 0.167 & 0.156 & 0.228 & 0.172 & 0.723 \\
Sewage sludge biochar & 0.272 & 0.172 & 0.611 & 0.122 & 1.177 \\
Pig manure biochar & 0.161 & 0.056 & 0.278 & 0.133 & 0.628 \\
\hline
\end{tabular}


Table S3 Formula of minimal medium (MM) solutions and plate

One liter MM solution contained $\mathrm{K}_{2} \mathrm{HPO}_{4}(6.0 \mathrm{~g}), \mathrm{KH}_{2} \mathrm{PO}_{4}(5.5 \mathrm{~g}), \mathrm{Na}_{2} \mathrm{SO}_{4}(2.0 \mathrm{~g})$, $\mathrm{KCL}(2 \mathrm{~g}), 1 \mathrm{ml}$ of trace element solution.

Trace element solution:

Nitrilotriacetic acid

$1.500 \mathrm{~g}$

$\mathrm{MgSO}_{4} \times 7 \mathrm{H}_{2} \mathrm{O}$

$3.000 \mathrm{~g}$

$\mathrm{MnSO}_{4} \times \mathrm{H}_{2} \mathrm{O}$

$0.500 \mathrm{~g}$

$\mathrm{NaCl}$

$1.000 \mathrm{~g}$

$\mathrm{FeSO}_{4} \times 7 \mathrm{H}_{2} \mathrm{O}$

$0.100 \mathrm{~g}$

$\mathrm{CoSO}_{4} \times 7 \mathrm{H}_{2} \mathrm{O}$

$0.018 \mathrm{~g}$

$\mathrm{CaCl}_{2} \times 2 \mathrm{H}_{2} \mathrm{O}$

$0.100 \mathrm{~g}$

$\mathrm{ZnSO}_{4} \times 7 \mathrm{H}_{2} \mathrm{O}$

$0.180 \mathrm{~g}$

$\mathrm{CuSO}_{4} \times 5 \mathrm{H}_{2} \mathrm{O}$

$0.010 \mathrm{~g}$

$\mathrm{KAl}(\mathrm{SO} 4)_{2} \times 12 \mathrm{H}_{2} \mathrm{O}$

$0.020 \mathrm{~g}$

$\mathrm{H}_{3} \mathrm{BO}_{3} \times \mathrm{H}_{2} \mathrm{O}$

$0.010 \mathrm{~g}$

$\mathrm{Na}_{2} \mathrm{MoO}_{4} \times 2 \mathrm{H}_{2} \mathrm{O}$

$0.010 \mathrm{~g}$

$\mathrm{NiCl}_{2} \times 6 \mathrm{H}_{2} \mathrm{O}$

$0.025 \mathrm{~g}$

$\mathrm{Na}_{2} \mathrm{SeO}_{3} \times 5 \mathrm{H}_{2} \mathrm{O}$

$0.300 \mathrm{mg}$

Distilled water $1000.000 \mathrm{ml}$

Extra $15 \mathrm{~g}$ of agar was added in one liter MM solution during the preparation of MM plate. 
Table S4 Residual PAH in CP soil with different treatments for 18 days

\begin{tabular}{|c|c|c|c|c|c|c|c|c|c|}
\hline \multirow[b]{3}{*}{$\mathrm{PAH}$} & \multirow[b]{3}{*}{$\begin{array}{l}\text { CP-0d } \\
\left(\mathrm{mg} \mathrm{kg}^{-1}\right)\end{array}$} & \multicolumn{8}{|c|}{ residual PAH $\left(\mathrm{mg} \mathrm{kg}^{-1}\right)$} \\
\hline & & \multicolumn{4}{|c|}{ without Brij 30} & \multicolumn{4}{|c|}{$2 \mathrm{mg} \mathrm{g}^{-1}$ Brij 30} \\
\hline & & CP-18d & CP-BC-18d & $\begin{array}{l}\text { СР-M. } \\
\text { gilvum -18d }\end{array}$ & $\begin{array}{l}\text { СР-ВC-M. } \\
\text { gilvum-18d }\end{array}$ & CP-18d & CP-BC-18d & $\begin{array}{l}\text { СР- } M . \\
\text { gilvum -18d }\end{array}$ & $\begin{array}{l}\text { СР-ВC-M. } \\
\text { gilvum-18d }\end{array}$ \\
\hline Naphthalene & $4.01 \pm 0.39$ & $3.84 \pm 0.53$ & $4.07 \pm 0.33$ & $4.07 \pm 0.33$ & $2.42 \pm 1.47$ & $4.48 \pm 0.74$ & $4.50 \pm 0.73$ & $4.34 \pm 0.01$ & $3.37 \pm 1.15$ \\
\hline Acenaphthylene & $9.81 \pm 0.60$ & $9.28 \pm 0.34$ & $9.90 \pm 0.83$ & $9.91 \pm 0.81$ & $8.90 \pm 0.63$ & $9.58 \pm 0.28$ & $8.99 \pm 0.59$ & $9.20 \pm 0.01$ & $8.18 \pm 0.83$ \\
\hline Acenaphthene & $2.69 \pm 1.05$ & $2.94 \pm 0.87$ & $2.26 \pm 0.18$ & $2.26 \pm 0.18$ & $1.91 \pm 0.85$ & $2.86 \pm 0.69$ & $2.85 \pm 0.68$ & $2.26 \pm 0.28$ & $2.15 \pm 0.65$ \\
\hline Fluorene & $6.67 \pm 1.87$ & $6.23 \pm 1.74$ & $6.37 \pm 0.51$ & $6.35 \pm 0.51$ & $4.93 \pm 1.31$ & $7.00 \pm 0.50$ & $6.99 \pm 0.50$ & $6.49 \pm 0.08$ & $5.90 \pm 0.68$ \\
\hline Phenanthrene & $73.74 \pm 3.75$ & $70.81 \pm 6.59$ & $65.89 \pm 3.46$ & $38.86 \pm 3.47$ & $27.59 \pm 17.33$ & $50.84 \pm 7.21$ & $50.82 \pm 7.21$ & $39.87 \pm 1.84$ & $35.36 \pm 1.21$ \\
\hline Anthracene & $16.89 \pm 0.46$ & $17.67 \pm 6.83$ & $14.00 \pm 1.00$ & $13.87 \pm 1.00$ & $11.13 \pm 2.73$ & $15.09 \pm 1.54$ & $15.06 \pm 1.60$ & $13.04 \pm 0.45$ & $13.25 \pm 2.00$ \\
\hline Fluoranthene & $108.34 \pm 6.09$ & $105.94 \pm 1.31$ & $105.97 \pm 2.82$ & $101.46 \pm 6.31$ & $51.91 \pm 2.51$ & $103.56 \pm 5.05$ & $91.27 \pm 3.01$ & $73.22 \pm 4.31$ & $77.44 \pm 11.29$ \\
\hline Pyrene & $122.20 \pm 4.34$ & $121.58 \pm 5.69$ & $105.75 \pm 3.46$ & $98.08 \pm 7.97$ & $46.26 \pm 1.09$ & $80.99 \pm 15.69$ & $100.63 \pm 4.68$ & $63.48 \pm 3.35$ & $62.47 \pm 8.67$ \\
\hline Benzo(a)anthracene & $49.52 \pm 2.19$ & $47.88 \pm 6.08$ & $45.73 \pm 4.65$ & $45.94 \pm 4.70$ & $44.87 \pm 0.92$ & $50.42 \pm 1.06$ & $45.02 \pm 1.60$ & $46.18 \pm 1.39$ & $49.47 \pm 5.10$ \\
\hline Chrysene & $66.59 \pm 2.23$ & $60.56 \pm 6.77$ & $62.80 \pm 8.50$ & $62.99 \pm 8.48$ & $62.86 \pm 1.55$ & $58.15 \pm 0.58$ & $61.69 \pm 0.22$ & $60.45 \pm 1.69$ & $62.12 \pm 8.08$ \\
\hline Benzo(b)fluorene & $46.55 \pm 2.31$ & $50.4 \pm 2.42$ & $50.71 \pm 3.48$ & $50.97 \pm 3.52$ & $29.71 \pm 2.47$ & $48.55 \pm 3.81$ & $46.91 \pm 2.79$ & $49.28 \pm 3.06$ & $47.22 \pm 5.62$ \\
\hline Benzo (k)fluorene & $42.87 \pm 2.46$ & $41.3 \pm 4.54$ & $42.82 \pm 1.83$ & $42.91 \pm 1.85$ & $41.32 \pm 7.90$ & $41.17 \pm 4.37$ & $37.96 \pm 4.87$ & $42.86 \pm 1.04$ & $39.45 \pm 10.55$ \\
\hline Benzo(a)pyrene & $53.92 \pm 8.72$ & $49.82 \pm 8.44$ & $54.73 \pm 7.82$ & $54.93 \pm 7.81$ & $47.07 \pm 3.32$ & $50.27 \pm 9.23$ & $52.07 \pm 9.05$ & $48.73 \pm 2.26$ & $47.45 \pm 4.84$ \\
\hline Indeno(1,2,3-cd)pyrene & $10.66 \pm 0.65$ & $10.83 \pm 0.13$ & $11.22 \pm 0.43$ & $11.24 \pm 0.39$ & $10.94 \pm 1.43$ & $12.56 \pm 0.26$ & $11.11 \pm 0.19$ & $11.62 \pm 0.15$ & $11.37 \pm 0.62$ \\
\hline Dibenzo(a,h)anthracen & $19.40 \pm 0.11$ & $16.43 \pm 2.8$ & $20.25 \pm 1.95$ & $20.25 \pm 1.87$ & $19.22 \pm 0.36$ & $20.79 \pm 0.58$ & $18.95 \pm 0.35$ & $17.40 \pm 0.32$ & $17.33 \pm 0.60$ \\
\hline Benzo(g,h,i)perylene & $34.10 \pm 1.51$ & $35.38 \pm 0.65$ & $33.47 \pm 2.64$ & $35.03 \pm 0.09$ & $36.85 \pm 2.13$ & $35.56 \pm 0.10$ & $33.37 \pm 1.97$ & $35.24 \pm 0.03$ & $35.39 \pm 0.06$ \\
\hline$\sum 16$ PAHs & $667.96 \pm 10.87$ & $644.88 \pm 13.25$ & $555.46 \pm 18.60$ & $596.13 \pm 28.85$ & $359.90 \pm 37.39$ & $581.88 \pm 20.53$ & $515.81 \pm 10.66$ & $488.65 \pm 6.23$ & $486.92 \pm 56.37$ \\
\hline
\end{tabular}


Table S5 Aqueous PAH insuspensions separated from soils with different treatments for 18 days

\begin{tabular}{|c|c|c|c|c|c|c|c|c|}
\hline \multirow[b]{3}{*}{ РAH } & & \multicolumn{7}{|c|}{ Aqueous PAH $\left(\mu \mathrm{g} \mathrm{L}^{-1}\right)$} \\
\hline & \multicolumn{4}{|c|}{ without Brij 30} & \multicolumn{4}{|c|}{$2 \mathrm{~g} \mathrm{~L}^{-1}$ Brij 30} \\
\hline & CP-18d & CP-BC-18d & $\begin{array}{l}\text { CР-M. } \\
\text { gilvum -18d }\end{array}$ & $\begin{array}{l}\text { СР-BC-M. } \\
\text { gilvum-18d }\end{array}$ & CP-18d & CP-BC-18d & $\begin{array}{l}\text { СР-M. gilvum } \\
-18 \mathrm{~d}\end{array}$ & $\begin{array}{l}\text { СР-ВC-M. } \\
\text { gilvum-18d }\end{array}$ \\
\hline Naphthalene & ND & ND & ND & ND & ND & ND & ND & ND \\
\hline Acenaphthylene & $27.1 \pm 3.6$ & $25.1 \pm 2.7$ & $20 \pm 2.4$ & $22.5 \pm 1.9$ & $127.1 \pm 10.3$ & $125.1 \pm 9.4$ & $115 \pm 11.9$ & $128.5 \pm 15.6$ \\
\hline Acenaphthene & $20.5 \pm 3.4$ & $14.5 \pm 2.6$ & $16.3 \pm 1.6$ & $15.8 \pm 1.3$ & $87.1 \pm 4.8$ & $91.2 \pm 6.4$ & $85.3 \pm 10.2$ & $90.6 \pm 6.8$ \\
\hline Fluorene & $14 \pm 2.9$ & $12.2 \pm 1.6$ & $10.2 \pm 1.8$ & $13.7 \pm 2.0$ & $140.8 \pm 14.2$ & $125.2 \pm 12.6$ & $130.71 \pm 14.9$ & $139.7 \pm 19.3$ \\
\hline Phenanthrene & $376.8 \pm 21.1$ & $358.1 \pm 58.3$ & $358.8 \pm 24.6$ & $391.4 \pm 9.2$ & $3168.1 \pm 105.7$ & $2981.5 \pm 292.1$ & $3288.9 \pm 112.9$ & 3014. $8 \pm 45.7$ \\
\hline Anthracene & $17.21 \pm 3.1$ & $12.1 \pm 2.3$ & $15.9 \pm 3.1$ & $13.4 \pm 1.2$ & $157.2 \pm 20.5$ & $102.1 \pm 6.7$ & $145.1 \pm 16.8$ & $123.2 \pm 13.3$ \\
\hline Fluoranthene & $31.14 \pm 7.5$ & $33.1 \pm 3.2$ & $35.7 \pm 7.6$ & $35.1 \pm 3.1$ & $211.4 \pm 23.4$ & $231.29 \pm 17.4$ & $257.57 \pm 16.0$ & $251.29 \pm 23.6$ \\
\hline Pyrene & $75.4 \pm 15.9$ & $81.8 \pm 1.6$ & $68.4 \pm 8.1$ & $81.8 \pm 1.5$ & $354.2 \pm 23.2$ & $318.7 \pm 5.8$ & $384.9 \pm 24.6$ & $328.7 \pm 9.2$ \\
\hline Benzo(a)anthracene & $14.6 \pm 4.2$ & ND & ND & ND & $93.7 \pm 19.6$ & $84.2 \pm 14.6$ & $69.1 \pm 13.3$ & $77.3 \pm 10.7$ \\
\hline Chrysene & $6.9 \pm 2.8$ & $4.2 \pm 1.1$ & $11.4 \pm 3.5$ & $8.2 \pm 3.1$ & $27.1 \pm 4.6$ & $22.2 \pm 2.6$ & $25.8 \pm 5.1$ & $28.6 \pm 7.0$ \\
\hline Benzo(b)fluorene & $49.2 \pm 1.3$ & $29.7 \pm 3.6$ & $38.2 \pm 4.6$ & $37.8 \pm 5.2$ & $46.2 \pm 4.5$ & $49.7 \pm 8.9$ & $52.2 \pm 5.4$ & $57.4 \pm 6.1$ \\
\hline Benzo (k)fluorene & ND & ND & ND & ND & $33.1 \pm 5.7$ & $37.1 \pm 7.8$ & $34.9 \pm 6.1$ & $38.6 \pm 5.2$ \\
\hline Benzo(a)pyrene & ND & ND & ND & ND & $57.2 \pm 4.7$ & $60.4 \pm 4.2$ & $55.8 \pm 3.7$ & $62.16 \pm 6.8$ \\
\hline Indeno(1,2,3-cd)pyrene & ND & ND & ND & ND & $18.7 \pm 3.7$ & $18.1 \pm 4.1$ & $17.7 \pm 4.6$ & $19.5 \pm 3.5$ \\
\hline Dibenzo(a,h)anthracen & $13.6 \pm 2.3$ & $10.5 \pm 3.8$ & $12.4 \pm 3.3$ & $14.9 \pm 3.7$ & $33.6 \pm 4.9$ & $36.4 \pm 5.8$ & $32.2 \pm 7.1$ & $34.7 \pm 4.6$ \\
\hline Benzo(g,h,i)perylene & ND & ND & ND & ND & $23.4 \pm 1.4$ & $22.7 \pm 5.3$ & $19.6 \pm 4.4$ & $24.7 \pm 3.2$ \\
\hline$\sum 16$ PAHs & $652.9 \pm 35.1$ & $581.3 \pm 24.6$ & $567.36 \pm 40.6$ & $634.6 \pm 29.7$ & $4578.8 \pm 106.9$ & $4305.8 \pm 112.3$ & $4714.8 \pm 136.4$ & $4419.7 \pm 125.8$ \\
\hline
\end{tabular}




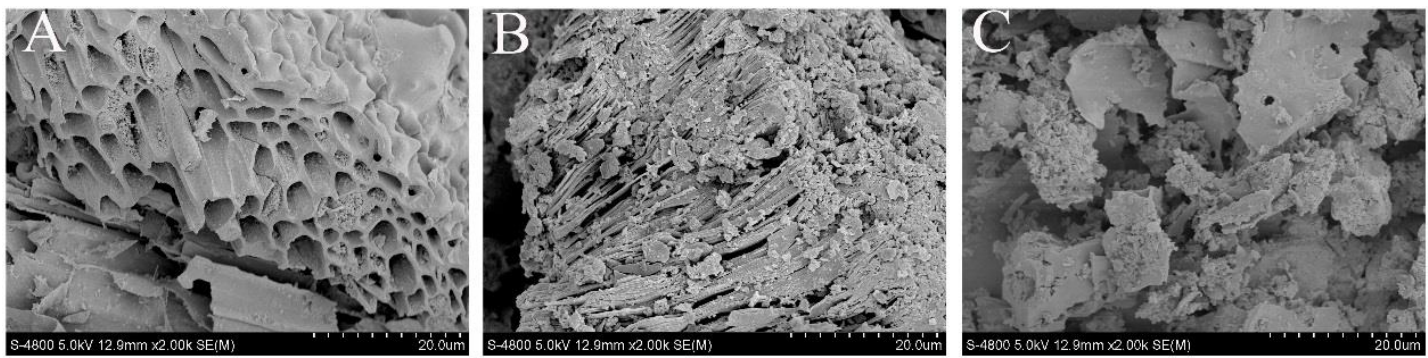

Figure S1. SEM image of biochar derived from different feedstocks: (A), rice straw biochar ( $\times 2000)$; (2) sewage sludge biochar $(\times 2000)$; and (3) pig manure biochar $(\times 2000)$. As evident in Figure S1, the surface structure of three biochars were varied 6 greatly: porous structure was commonly observed in rice straw biochar; whereas on sewage sludge and pig manure biochar, it was faultage and bulk aggregates. The existence of suitable pores within the rice straw biochar was evident in the SEM image of Figure S1 (A), indicating that rice straw biochar was more suitable carrier for microbial immobilization than sewage sludge and pig manure biochar.

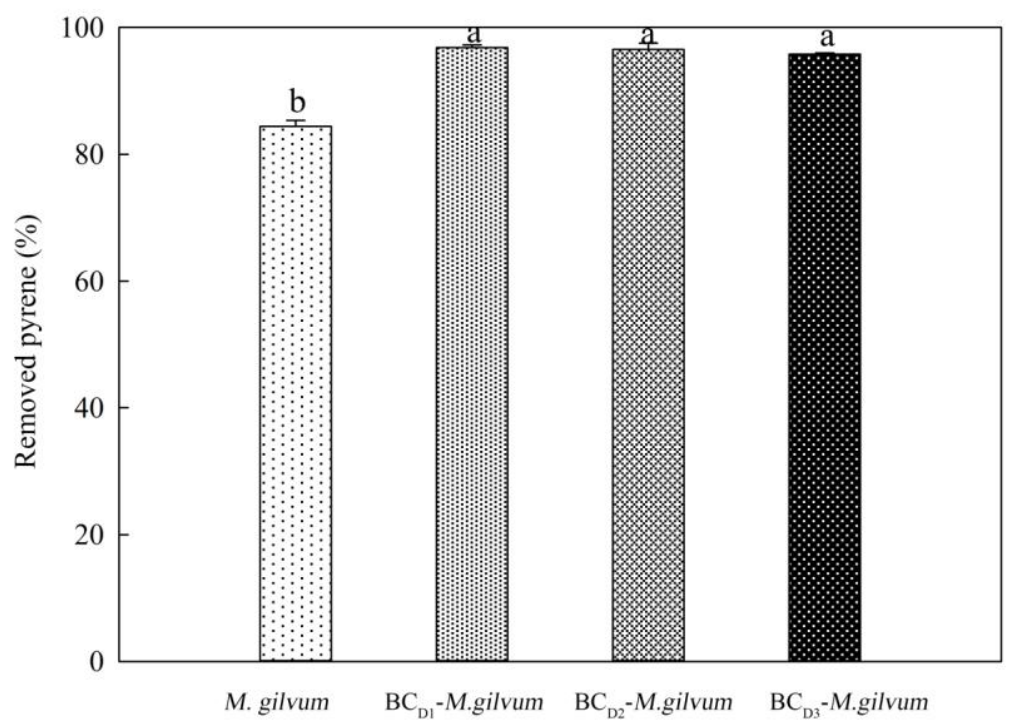


13 Figure S2. Biodegradation of 9 PAHs by $M$. 14 gilvum in MM solutions. M. gilvum was 15 confirmed to be capable of degrading 16 naphthalene (NAP), fluorene (FLU), ${ }_{17}$ phenanthrene (PHE), anthracene (ANT), 18 pyrene (PYR), and fluoranthene (FLA). 19 Benzo(a)pyrene (BAP) was partially 20 degraded. No significant difference in ${ }_{21}$ acenaphthylene (AYL) and acenaphthene ${ }_{22}$ (ACE) concentrations was observed for 823 day incubation ( $P=0.964,1.000$ for $A Y L$ and ${ }_{24}$ ACE respectively), indicating $M$. gilvum was 25 not able to use both AYL and ACE as solo 26 sources of carbon and energy. These results 27 agree with other reports.(Kim, Park et al. 28 2001) 


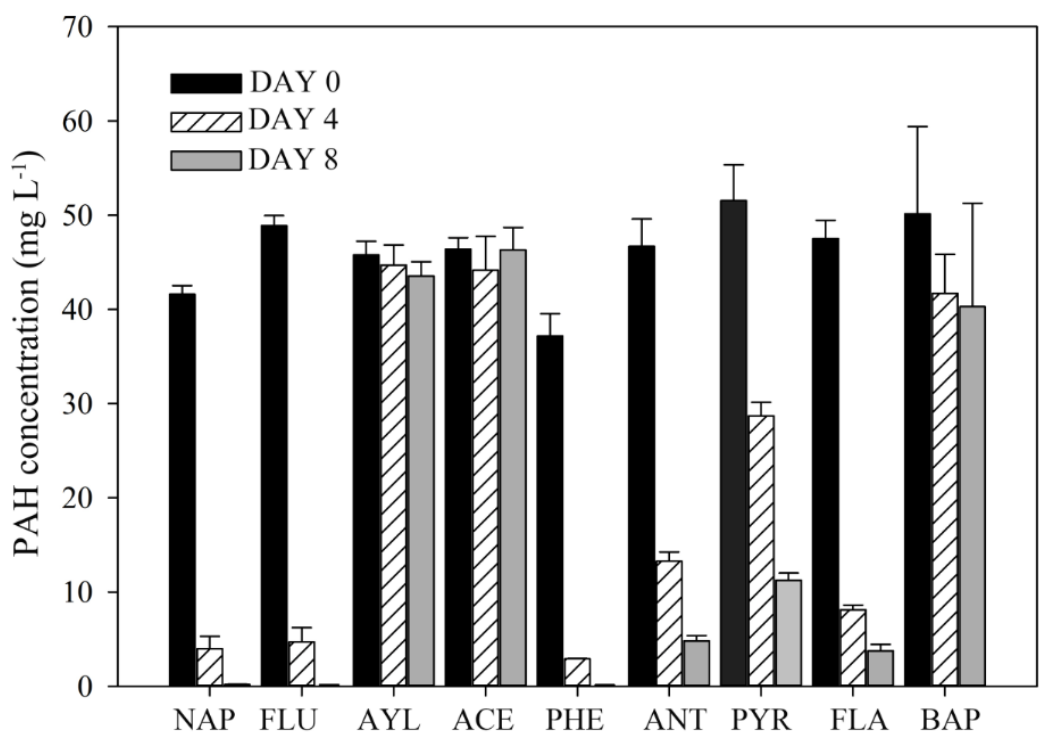


31 Figure S3. Removal of pyrene in minimal 32 medium solution with different treatments for 5

33 days. Removal of pyrene was significantly ${ }_{34}$ increased in the presence of biochar 35 immobilized with $M$. gilvum cells $(\mathbf{P}<0.05)$, 36 regardless of biochar particle size. 37 Abbreviations: $\quad \boldsymbol{M}$. $\quad$ gilvum-free 38 Mycobacterium gilvum, $\mathrm{BC}_{\mathrm{D} 1-\mathrm{D} 3-M}$. gilvum39 Mycobacterium gilvum cells immobilized on 40 biochar with particle size ranging from ${ }_{41} \quad 0.25 \mathrm{~mm}-2 \mathrm{~mm}$ (D1), 0.15mm 0.25mm (D2), ${ }_{42}$ and $<0.15 \mathrm{~mm}$ (D3) respectively. Sample 43 numbers $\mathbf{n}=\mathbf{3}$, error bar $=\mathbf{1}$ standard ${ }_{44}$ deviation. Different lower-case letters 45 indicate the mean difference is significant 46 between treatments at the 0.05 level. 

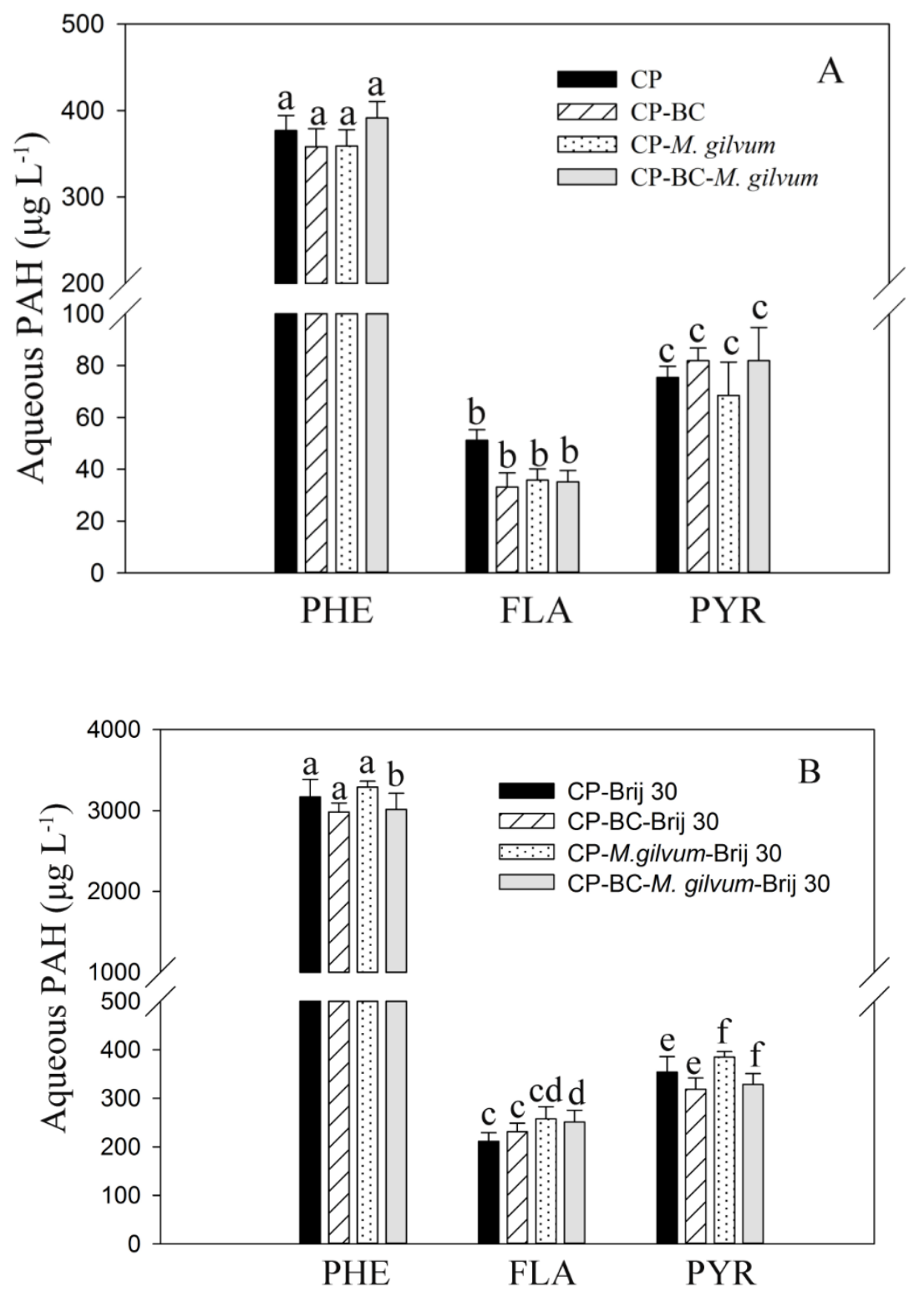
Figure S4. Aqueous PAH concentration in suspensions separated from soils with different treatments for 18 days. Panel A: Treatments without Brij 30 amendment. Panel B: treatments with $2 \mathrm{mg} \mathrm{g}_{\text {soil }}{ }^{-1}$ Brij 30 . Abbreviations: $\mathrm{CP}$ - raw CP soil only; CP$\mathrm{BC}-\mathrm{CP}$ soil with sterile rice straw biochar. CP-M. gilvum- CP soil with free Mycobacterium gilvum cells inoculation. CPBC-M. gilvum-CP soil with biochar impregnated $M$. gilvum amendment

\section{Extended Discussion of Figure S4}

In Figure S4A, similar water-dissolved $\mathrm{PAH}$ concentrations were detected in solutions separated from soils with four different treatments. Mean porewater solution concentrations of PHE, FLA, and PYR were 371.33 $\pm 8.38,38.79 \pm 6.13,76.91 \pm 6.39 \mu \mathrm{g}$

$\mathrm{L}^{-1}$. Those values were a little higher than concentrations of porewater solutions of PAHs reported in analogous studies (Beesley, Moreno-Jiménez et al. 2010). This may be attributed the presence of dissolved organic carbon (DOC), such as originating from extracellular polymeric substances, increases the number of dissolved sorption sites for PAHs, enhancing the fraction of PAHs into the aqueous phase (and lowering apparent $\mathrm{K}_{\mathrm{D}}$ values based on total aqueous concentration). 
74

Beesley, L., E. Moreno-Jiménez and J. L. Gomez-Eyles (2010). "Effects of biochar and greenwaste compost amendments on mobility, bioavailability and toxicity of inorganic and organic contaminants in a multi-element polluted soil." Environmental pollution 158(6): 2282-2287.

Boehm, H. (2002). "Surface oxides on carbon and their analysis: a critical assessment." Carbon 40(2): 145-149.

Fabbri, D., A. G. Rombolà, C. Torri and K. A. Spokas (2013). "Determination of polycyclic aromatic hydrocarbons in biochar and biochar amended soil." Journal of Analytical and Applied Pyrolysis 103: 60-67.

Kim, I. S., J.-S. Park and K.-W. Kim (2001). "Enhanced biodegradation of polycyclic aromatic hydrocarbons using nonionic surfactants in soil slurry." Applied Geochemistry 16(11): 1419-1428.

Miller, W. and D. Miller (1987). "A micro-pipette method for soil mechanical analysis." Communications in Soil Science \& Plant Analysis 18(1): 1-15. 